\title{
Characterization of age-related gene expression profiling in bone marrow and epididymal adipocytes
}

\author{
Li-Fen Liu' ${ }^{1,2}$, Wen-Jun Shen ${ }^{1,2}$, Masami Ueno ${ }^{1,2}$, Shailja Patel ${ }^{1,2}$ and Fredric B Kraemer ${ }^{1,2^{*}}$
}

\begin{abstract}
Background: While an increase in bone marrow adiposity is associated with age-related bone disease, the function of bone marrow adipocytes has not been studied. The aim of this study was to characterize and compare the agerelated gene expression profiles in bone marrow adipocytes and epididymal adipocytes.

Results: A total of 3918 (13.7\%) genes were differentially expressed in bone marrow adipocytes compared to epididymal adipocytes. Bone marrow adipocytes revealed a distinct gene profile with low expression of adipocytespecific genes peroxisome proliferator-activated receptor gamma (PPAR $\gamma$ ), fatty acid binding protein 4 (FABP4), perilipin (Plin1), adipsin (CFD) and high expression of genes associated with early adipocyte differentiation (CCAAT/ enhancer binding protein beta (C/EBP $\beta$ ), regulator of G-protein signaling 2 (RGS2). In addition, a number of genes including secreted frizzled related protein 4 (SFRP4), tumor necrosis factor $\alpha$ (TNF $\alpha$ ), transforming growth factor beta 1(TGFß 1), G-protein coupled receptor 109A (GPR109A) and interleukin 6 (IL-6), that could affect adipose-derived signaling to bone are markedly increased in bone marrow adipocytes. Age had a substantial effect on genes associated with mitochondria function and inflammation in bone marrow adipocytes. Twenty seven genes were significantly changed with age in both adipocyte depots. Among these genes, IL6 and GPR109A were significantly reduced with age in both adipocyte depots.

Conclusions: Overall, gene profiling reveals a unique phenotype for primary bone marrow adipocytes characterized by low adipose-specific gene expression and high expression of inflammatory response genes. Bone marrow and epididymal adipocytes share a common pathway in response to aging in mice, but age has a greater impact on global gene expression in epididymal than in bone marrow adipocytes. Genes that are differentially expressed at greater levels in the bone marrow are highly regulated with age.
\end{abstract}

\section{Background}

Aging is associated with impaired adipogenesis in various fat depots in humans [1-4]. With age and age-related osteoporosis, there is an inverse relationship between bone mass and bone marrow adiposity [5-7]. There are generally considered to be two types of adipose tissue, white and brown, both of which are able to store lipid but have different roles in energy metabolism [8,9]. Moreover, there are regional differences in the function among various adipose tissue depots; in humans visceral obesity presents a

\footnotetext{
* Correspondence: fbk@stanford.edu

'Division of Endocrinology, Stanford University, Stanford, CA, 94305-5103, USA

Full list of author information is available at the end of the article
}

greater risk for obesity-related metabolic disease than subcutaneous obesity $[10,11]$.

Previous functional studies of marrow adipocytes have mostly been limited to developmental studies [12]. Some studies have suggested that the presence of adipocytes can influence differentiation of mesenchymal stem cells (MSCs) into adipocytes, thereby inhibiting the differentiation into other cell lines [13]. We and others reported that directly co-culturing bone marrow MSCs with fully differentially adipocytes decreased osteoblast differentiation by decreasing RunX2 mRNA expression [14,15], suggesting that these cells are metabolically active but negatively regulate differentiation of MSCs into osteoblasts. Recent studies have suggested that, in addition to adipose, liver and muscle tissue, the osteoblast is also an important target
C Biomed Central

(C) 2011 Liu et al; licensee BioMed Central Ltd. This is an Open Access article distributed under the terms of the Creative Commons Attribution License (http://creativecommons.org/licenses/by/2.0), which permits unrestricted use, distribution, and reproduction in any medium, provided the original work is properly cited. 
tissue for insulin action $[16,17]$. Infiltration of fat in bone marrow could affect osteoblast function and differentiation through paracrine/endocrine effects of secretory products and adipocytokines $[18,19]$. Thus, bone marrow adipocytes might play a pivotal role in mediating the regulation of osteoblast function in aging and in diabetic or obese animals. A recent report demonstrated that bone marrowderived adipocytes are distinct from epididymal white adipocytes [20]. While it is well known that ectopic fat accumulation in non-adipose tissues is greatly associated with age-related insulin resistance and metabolic disorders [21], the relationship of bone marrow adiposity with agerelated diseases is unclear. In view of the specialized environment within the bone marrow with both active hematopoiesis and osteoblastogenesis ongoing, we hypothesized that adipocytes within the bone marrow might constitute a unique depot. In order to obtain a comprehensive understanding of the characteristics of bone marrow adipocytes, we profiled the gene expression patterns in bone marrow adipocytes with age and simultaneously examined differential gene expression in bone marrow and epididymal adipocytes with age. This study is the first to characterize primary bone marrow adipocytes and to demonstrate the effects of aging on two different adipocyte populations within the same animal. Our results demonstrate that while bone marrow adipocytes are distinct from epididymal white adipocytes, they also share a common inflammatory pathway in response to aging.

\section{Results}

Table 1 depicts several metabolic and biochemical parameters of the mice included in these studies. The metabolic parameters showed the expected negative effects of age on mice. Thus, there was a significant increase in weight and serum insulin and glucose levels in older mice compared to 6 month old animals. These negative

Table 1 Metabolic parameters in aging mice

\begin{tabular}{llcc}
\hline Parameter & & 6-month & 14-month \\
\hline \multirow{5}{*}{ Adipokines } & Weight $(\mathrm{g})$ & $35.0 \pm 1.2$ & $41.8 \pm 4.0^{*}$ \\
& Insulin $(\mathrm{ng} / \mathrm{mL})$ & $0.57 \pm 0.16$ & $2.09 \pm 0.44^{*}$ \\
& Glucose $(\mathrm{mg} / \mathrm{dL})$ & $118.7 \pm 12$ & $192.7 \pm 17^{*}$ \\
& Triglyceride $(\mathrm{mg} / \mathrm{dL})$ & $240.9 \pm 3.43$ & $250.7 \pm 6.8$ \\
& Leptin $(\mathrm{ng} / \mathrm{mL})$ & & \\
& Resistin $(\mathrm{ng} / \mathrm{mL})$ & $1.35 \pm 0.17$ & $1.85 \pm 0.20$ \\
& Adiponectin $(\mu \mathrm{g} / \mathrm{mL})$ & $2.90 \pm 0.20$ & $5.66 \pm 0.74^{*}$ \\
Bone panel & & \\
& & $54.4 \pm 4.8$ & $31.8 \pm 6.8^{*}$ \\
& Osteocalcin $(\mathrm{ng} / \mathrm{mL})$ & $0.21 \pm 0.03$ & $0.17 \pm 0.22$ \\
& RANKL $(\mathrm{ng} / \mathrm{mL})$ & $2.28 \pm 0.40$ & $1.92 \pm 0.17$ \\
& Osteoprotegerin $(\mathrm{ng} / \mathrm{mL})$ & &
\end{tabular}

Data are mean \pm SE of 6 to 10 mice per age group. Body weights were determined at time of necropsy. Serum metabolites were measured in the fed state. ${ }^{*} P<0.05$ vs. 6 -month-old. metabolic effects of age were accompanied with significant increases in fat infiltration into bone marrow, as shown in Figure 1. Similarly, there were significant increases in leptin and adiponectin with age along with a significant decrease in circulating osteocalcin with age, whereas resistin, RANKL (receptor activator for nuclear factor $\kappa \mathrm{B}$ ligand) and osteoprotegerin showed no changes with age.

\section{Adipocyte-specific genes in bone marrow adipocytes}

Bone marrow adipocytes were isolated by flushing out bone marrow cells from femurs and tibias and then isolating the adipocytes by flotation. White adipocytes were isolated from epididymal adipose tissue by flotation following collagenase digestion. Figure 2A displays the characteristics of the adipocyte cell preparations from bone marrow and epididymal depots. Epididymal adipocytes tended to be larger, but both adipocyte populations stained neutral lipids with Bodipy. In order to evaluate the degree of contamination of the cell preparations with monocyte/macrophages, the percentage of monocytes present in the samples was determined by identifying the number of CD11b positive cells. Approximately 10-17\% of cells were identified as CD11b positive in both bone marrow and epididymal white adipocyte preparations (Figure 2A). In addition, the adipocytes from both bone marrow and epididymal depots stained with perilipin, but epididymal adipocytes had greater immunostaining. We verified the expression of a select group of adipocyte specific genes in the isolated adipocytes by RT-PCR (Reverse transcription polymerase chain reaction). FABP4 (fatty acid binding protein 4 , adipocyte), perilipin (Plin 1 ), ADFP (Plin2), leptin, adiponectin and C/EBP $\beta$ (CCAAT/ enhancer binding protein beta) were all much more highly expressed in bone marrow adipocytes compared to the non-floating bone marrow stromal cells, as would be expected for adipocyte specific genes (Figure 2B). However, all of these genes, except $\mathrm{C} / \mathrm{EBP} \beta$, were expressed at relatively lower levels in bone marrow compared to epididymal adipocytes. The differences in expression levels between bone marrow and epididymal adipocytes determined by qRT-PCR were mostly in agreement with the microarray data obtained (see below).

\section{Global characteristics of bone marrow adipocytes}

We analyzed the differential expression of adipocyte genes isolated from bone marrow and epididymal fat depots from adult (6-month-old) and aged mice (14-and 18month-old) using microarrays. Inspection of the frequency of expression values after normalization of the data showed consistent values between all samples (Additional File 1, Figure S1). Principal component analysis revealed a visible separation between bone marrow and epididymal adipocytes (Figure 3A). Moreover, there is a clear separation between epididymal adipocytes from 18-month and 
A

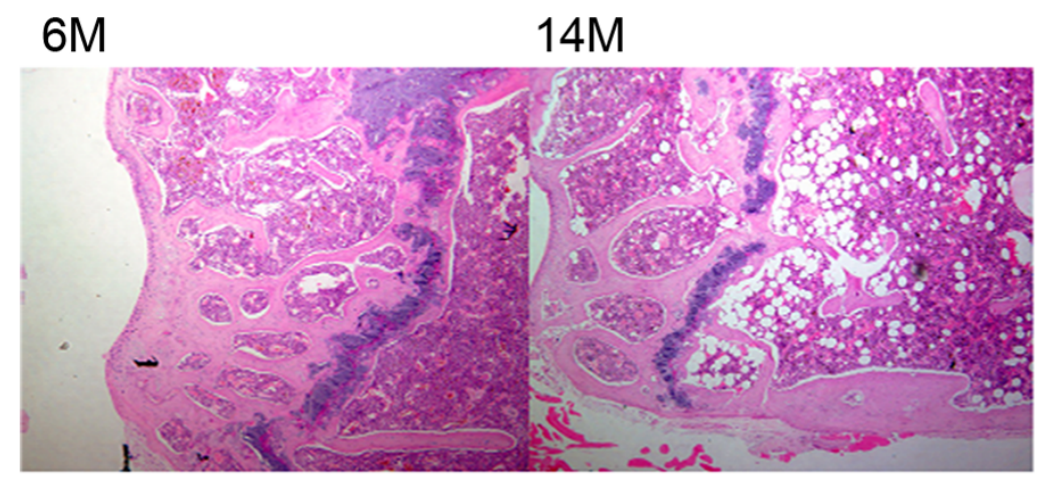

$5 X$

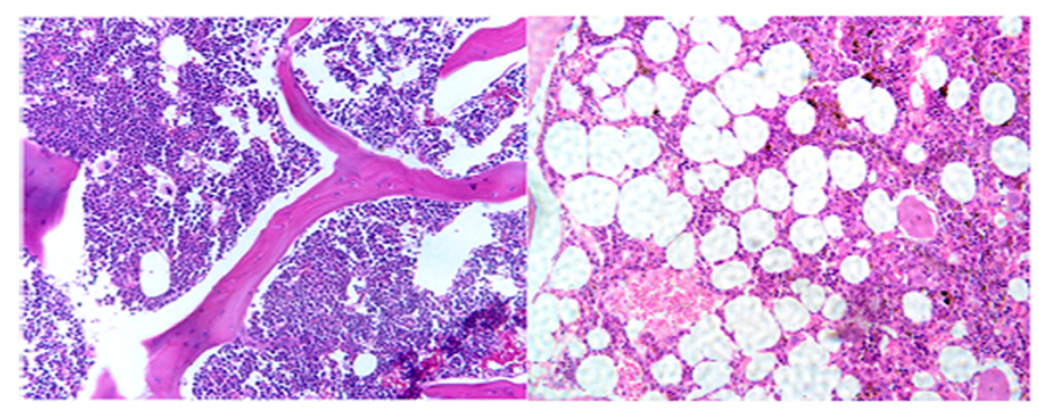

B

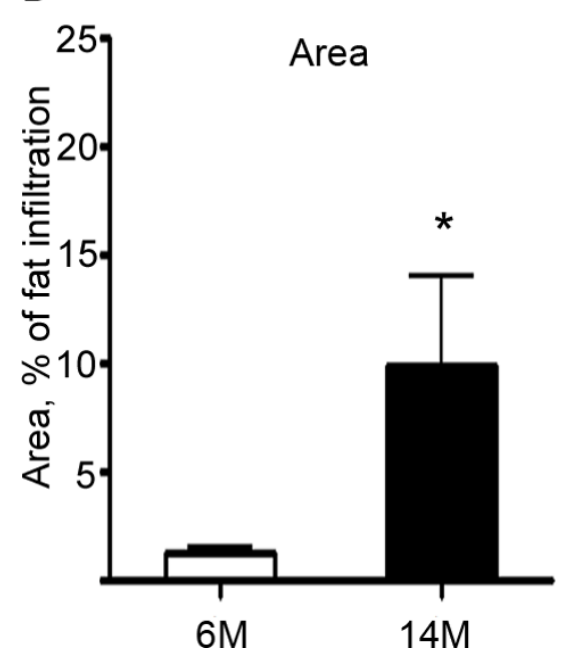

C

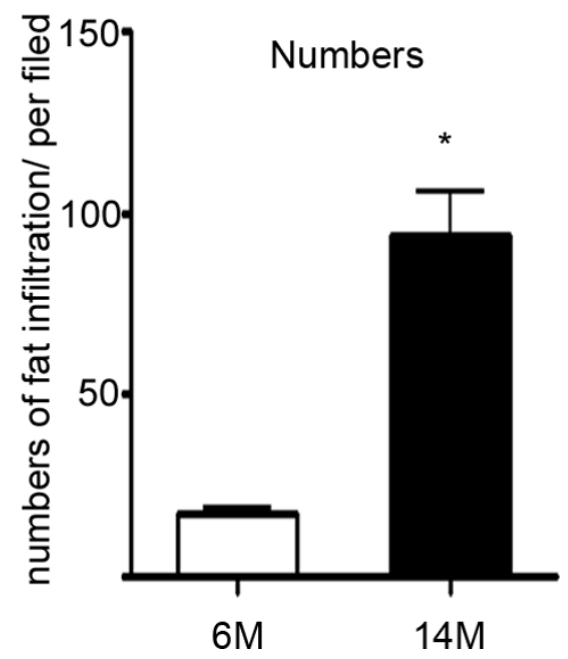

Figure 1 Quantitative analysis of bone marrow adipocytes. A. The top panels are images of the distal femurs from 6-month-old and 14month-old C57BL6/J male mice stained with H\&E (magnification $\times 5$ ). The bottom panels are sections stained with H\&E showing the numerous large adipocytes in bone marrow from distal femurs (magnification $\times 20$ ). B. Area of bone marrow fat infiltration as a \% of total area. C. Numbers of bone marrow fat cells (numbers $/ \mathrm{mm}^{2}$ bone marrow). Fields were taken from distal femur sections of 6-month-old and 14-month-old mice and calculated using ImagePro software.

younger mice. This clustering represents the overall expression patterns, but does not provide the expression of individual genes. Analysis of genes based on functional category was performed to measure the differences and the similarities between the two adipocyte populations. A total of 3918 (13\%) of the 28853 well-characterized mouse genes were differentially expressed between the two adipocyte populations. This selection was based on adjusted $\mathrm{p}<$ 0.05 and a fold change \pm 2.0 . These 3918 genes were assigned to biologically meaningful gene ontology (GO) 
A

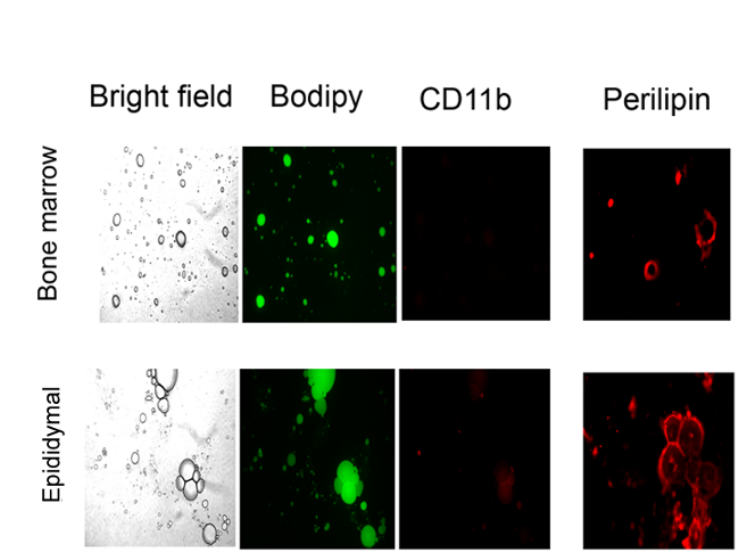

B

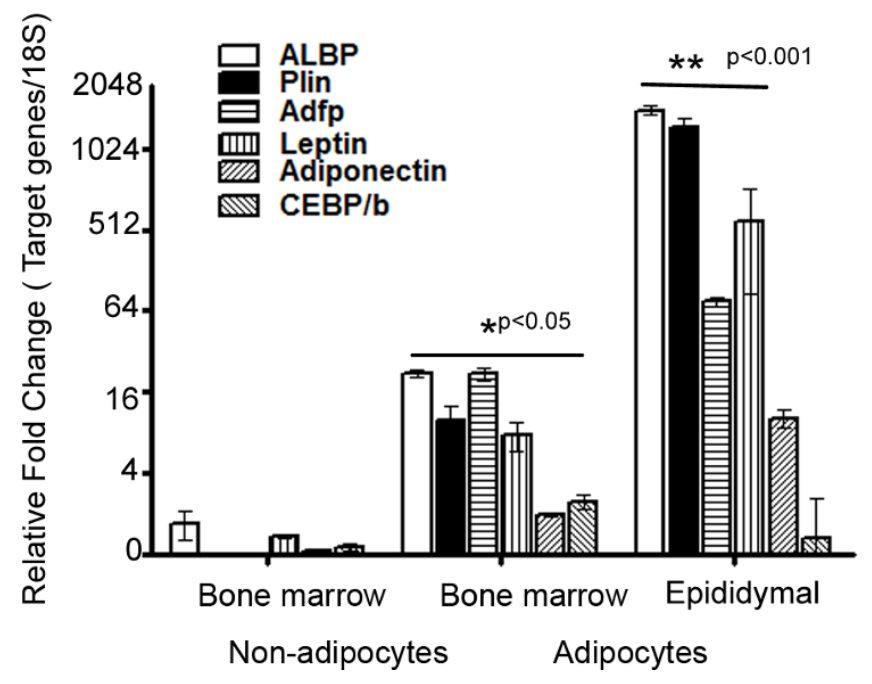

Figure 2 Characterization of adipocyte preparations isolated from bone marrow and epididymal depots. A. Light and immunofluorescence microscopy of adipocytes isolated from bone marrow and epididymal white adipose tissue. Fixed cells were incubated with either BODIPY 493/503 (1:500) or PE (phycoerythrin) conjugated anti-mouse CD11b (Intergrin a, Mac-1 $\alpha$ ) and polyclonal anti rabbit perilipin antibodies (1:200) in 1\% blocking solution for $1 \mathrm{~h}$. Following $1 \mathrm{~h}$ incubation of Alexa 555 (red) conjugated secondary antibodies at a dilution of $1 / 800$ at room temperature, the stained cells were washed three to four times with PBS and observed using a Zeiss microscope observer A1. B. Expression of selected adipose genes in preparations of bone marrow cells, adipocytes isolated from bone marrow and adipocytes isolated from epididymal adipose tissue. A set of original RNA from the same animal was re-amplified to aRNA, then converted to cDNA. Relative fold change was normalized to endogenous $18 \mathrm{~S}$ and bone marrow stromal cells. Data are presented as Log2 of fold change.

categories. Differences in gene expression between bone marrow and epididymal adipocytes were primarily observed in three categories: biological process, molecular function and cellular component (Table 2). Subcategories of biological process include regulation of cell cycle, cell death and cell differentiation and regulation of metabolic processes, for instance carbohydrate and lipid metabolism, whereas molecular function includes genes associated with protein binding, enzyme activity and transcription regulator activity, and cellular component includes genes that are associated with the cell membrane, extracellular matrix, synapses and membrane bound organelles. The table displays the enrichment score and $p$-value in subcategories of the overall category of biological processes that are most relevant to adipocyte-specific functions, whereas the subcategories of cellular component and molecular function are not shown because the $p$-value of these overall categories did not reach statistical significance. As shown in Table 2, fat cell differentiation comprised 71$74 \%$ of genes in the ontology functional analysis. We next loaded this set of 3918 genes differentially expressed in the bone marrow and epididymal adipocytes into Ingenuity Pathway Analyses for further biological functional analysis. A set of 277 genes was generated by filtering expression in adipose tissue. This set of genes displayed a substantial differential expression pattern between bone marrow and epididymal adipocytes (Table 3 ). Table 3 displays the genes that were most differentially expressed and that are associated with network and biological pathways in adipocytes. Of these 277 genes, supervised hierarchical clustering of 28 genes that are associated with the adipocyte phenotype revealed that all were expressed in bone marrow adipocytes and that their expression patterns differed markedly from epididymal adipocytes (Figure 3B). In contrast to Figure 3A, there appears to be a separation between 6-month-old and elder mice in expression of some of these adipose-specific genes in epididymal adipocytes in Figure 3B; however, it is important to note that Figure 3A represents global, not individual, gene differences.

\section{Functional analysis of differential gene expression} between bone marrow and epididymal white adipocytes We further analyzed the over-represented 3918 genes (2fold change) by GO enrichment (Partek) and Ingenuity Pathway analyses. Among these genes, a set of 1940 genes was decreased greater than 2 -fold $(p \leq 0.05)$ in bone marrow adipocytes compared with epididymal adipocytes across age. Of these 1940 genes, there were 547 genes associated with bio-functional groups and networks. This set of genes was enriched and associated with lipid metabolism, molecular transport and small molecule biochemistry. Figure 4A shows a supervised hierarchal cluster of genes related to adipocyte lipid metabolism, including 


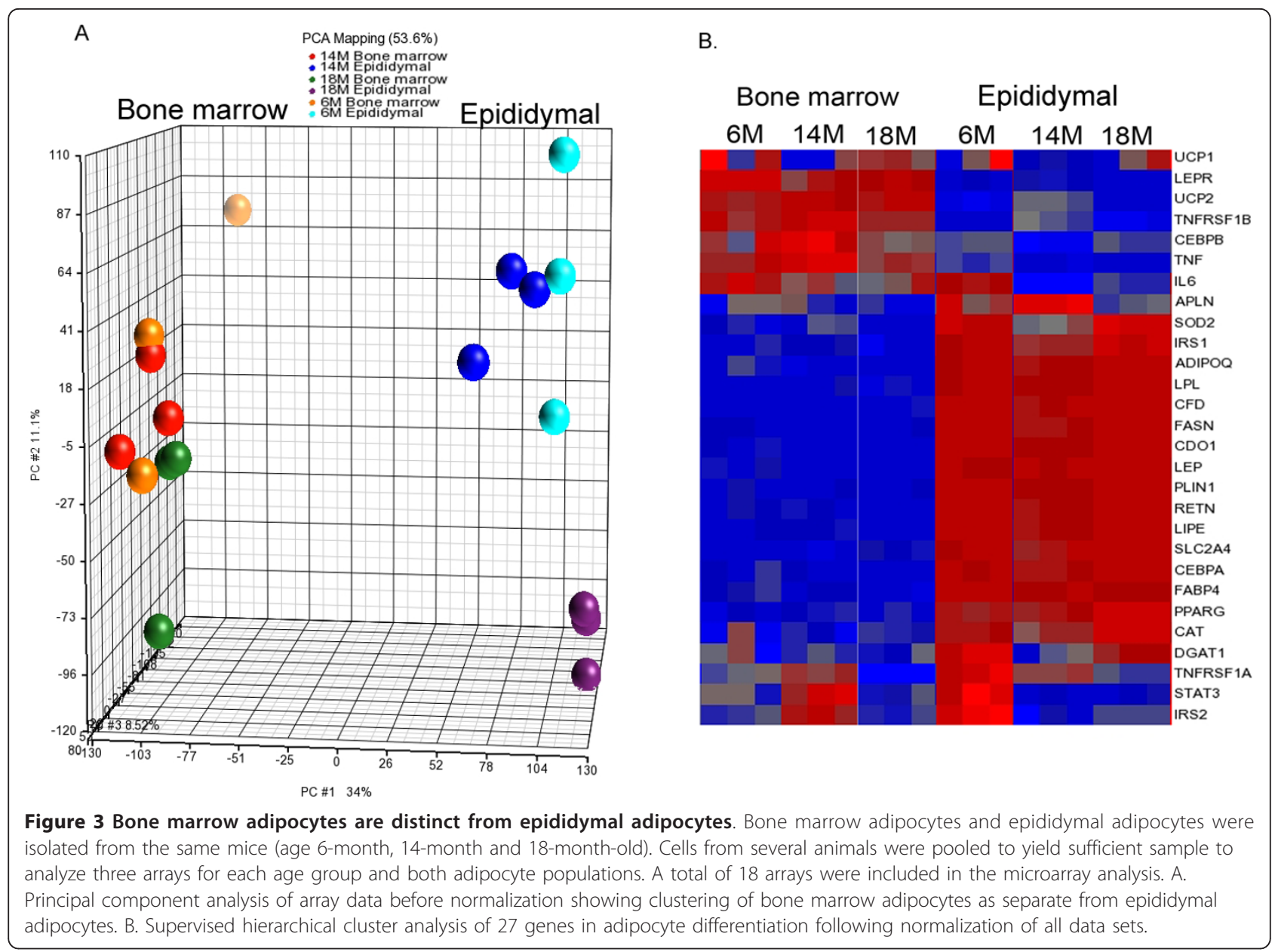

Table 2 Gene ontologies with differentially expressed genes in bone marrow adipocytes

\begin{tabular}{lccc}
\hline Functional Group & Enrichment Score* & $\boldsymbol{P}$ value** & \% genes in group present \\
\hline Biological process & 4.39 & 0.01 & 18.10 \\
$\quad$ Cellular & 40.9 & $<0.001$ & 21.9 \\
Immune system & 18.36 & $<0.001$ & 31.7 \\
Metabolic & 16.67 & $<0.001$ & 20.7 \\
Oxidation reduction & 37.36 & $<0.001$ & 30.52 \\
Lipid & 23.63 & $<0.001$ & 34.7 \\
Carbohydrate & 7.41 & $<0.001$ & 28.05 \\
Developmental & 4.3 & 0.01 & 19.71 \\
Adipocyte differentiation & 18.3 & $<0.001$ & 47.27 \\
$\quad$ Brown & 31.44 & $<0.001$ & 74.07 \\
$\quad$ White & 8.46 & $<0.001$ & 71.43 \\
Cellular component & 3.55 & 0.03 & 17.97
\end{tabular}

A selection of genes generated from ANOVA analysis was assigned to biologically meaningful gene ontology (GO) categories using GO enrichment analysis (Partek ${ }^{\mathbb{B}}$ Genome Suite software, version 6.3). Listed are groups of gene-associated biological processes in bone marrow adipocytes compared with epididymal adipocytes (fold change cut off is 2.0 ). ${ }^{*} \mathrm{~A}$ high value of enrichment score indicates that the functional group is over-represented in the gene list. ${ }^{* *} P$ value is the $-\log p$-value of a Chi-square test. 
Table 3 Comparison of adipocyte-genes between bone marrow and epididymal adipocytes

\begin{tabular}{|c|c|c|c|c|}
\hline Symbol & Entrez Gene Name & 6-month & 14-month & 18-month \\
\hline \multicolumn{5}{|c|}{ Increased expression in bone marrow } \\
\hline LEPR & leptin receptor & 19.7 & 7.4 & 16.4 \\
\hline OSM & oncostatin M & 18.1 & 20.1 & 11.4 \\
\hline RGS2 & regulator of G-protein signaling 2, 24kDa & 15.3 & 15.8 & 8.9 \\
\hline SFRP4 & secreted frizzled-related protein 4 & 14.8 & 1.8 & 6.6 \\
\hline ABCB4 & ATP-binding cassette, sub-family B, member 4 & 10.7 & 6.9 & 7.4 \\
\hline TNFRSF1 $\beta$ & CD120b & 6.6 & 4.3 & 8.3 \\
\hline TNF $\alpha$ & tumor necrosis factor $\alpha$ & 5.0 & 26.3 & 7.2 \\
\hline 100001G20RIK & RIKEN cDNA $1100001 \mathrm{G} 20$ gene, Wdnm1-like & 4.2 & 4.5 & 3.0 \\
\hline UCP2 & uncoupling protein 2 & 4.0 & 2.1 & 3.7 \\
\hline LPIN2 & lipin 2 & 4.0 & 3.9 & 5.6 \\
\hline TGFB1 & transforming growth factor, beta 1 & 3.9 & 2.5 & 3.8 \\
\hline GPR109A & G protein-coupled receptor 109A & 3.7 & 33.6 & 2.3 \\
\hline C/EBP $\beta$ & CCAAT/enhancer binding protein beta & 2.3 & 6.8 & 1.3 \\
\hline IL6 & interleukin 6 & $-1.1^{*}$ & 8.8 & 2.8 \\
\hline \multicolumn{5}{|c|}{ Decreased expression in bone marrow } \\
\hline LEP & leptin & -152.5 & -300.1 & -454.4 \\
\hline CFD & complement factor D (adipsin) & -138.2 & -115.9 & -107.1 \\
\hline RETN & resistin & -114.7 & -87.4 & -153.7 \\
\hline CDO1 & cysteine dioxygenase, type I & -106.9 & -132.3 & -192.1 \\
\hline PLIN1 & perilipin 1 & -100.6 & -85.1 & -106.5 \\
\hline ERPINE1 & plasminogen activator inhibitor type 1 & -60.9 & -7.0 & -19.0 \\
\hline FASN & fatty acid synthase & -32.9 & -28.5 & -43.5 \\
\hline ADIPOQ & adiponectin & -26.4 & -35.3 & -41.2 \\
\hline FABP4 & fatty acid binding protein 4 , adipocyte & -23.2 & -27.0 & -41.3 \\
\hline LIPE & lipase, hormone-sensitive & -21.9 & -15.2 & -26.8 \\
\hline LPL & lipoprotein lipase & -21.8 & -18.8 & -23.9 \\
\hline KLB & klotho beta & -21.1 & -12.9 & -29.6 \\
\hline ACOX1 & acyl-Coenzyme A oxidase 1, palmitoyl & -16.5 & -10.2 & -12.8 \\
\hline FGFR1 & fibroblast growth factor receptor 1 & -12.2 & -11.4 & -10.2 \\
\hline SLC2A4 & glucose transporter member 4 & -10.2 & -9.5 & -9.2 \\
\hline C/EBP $\alpha$ & CCAAT/enhancer binding protein, alpha & -6.7 & -8.7 & -11.2 \\
\hline PPAR $\gamma$ & peroxisome proliferator-activated receptor gamma & -5.9 & -4.8 & -10.3 \\
\hline $\mathrm{IDH} 1$ & isocitrate dehydrogenase $1(\mathrm{NADP}+)$, soluble & -5.1 & -4.7 & -6.4 \\
\hline ADIPOR2 & adiponectin receptor 2 & -4.7 & -4.0 & -4.7 \\
\hline
\end{tabular}

The list includes the most differentially expressed genes in bone marrow adipocytes compared to epididymal adipocytes. The set of the significantly differentially expressed genes was selected on the basis of their expression in adipose cells according to the IPA knowledge-base. For each gene, the fold change value in gene expression was calculated between mean values in bone marrow adipocytes versus epididymal adipocytes in mice (6-month, 14-month and 18-month old). The significance of differences was measured by one-way ANOVA. All values are $p<0.01$ except $* P>0.01$

fatty acid synthesis (upper panel) and oxidation (lower panel), that were 2-fold lower in bone marrow adipocytes. This gene set included leptin, Acsl1 (acyl-coA synthetase 1 ), adiponectin and Scap (SREBF chaperone) in fatty acid synthesis and PPAR $\alpha$, PGC1 $\alpha$, CPT $1 \alpha$ and ACOX1 in fatty acid oxidation. Clustering also highlighted a group of 1965 genes that were increased 2-fold or more in bone marrow adipocytes. Of these 1965 genes, there were 337 genes associated with biological function networks. These genes are associated with pro-apoptosis, pro-inflammatory cytokines and mitochondrial dysfunction. As listed in Table 3, genes displaying increased expression in bone marrow adipocytes include leptin receptor (Lepr), G-protein coupled receptor 109A (GPR109A) and gp-130 cytokines, oncostatin $\mathrm{M}(\mathrm{OM})$, interleukin 6 (IL-6) and TNF $\alpha$. Adipocyte specific genes (PPAR $\gamma$, FABP4, perilipin, adipsin and leptin) were expressed at significantly lower levels in bone marrow adipocytes compared with epididymal adipocytes. Figure 4B shows a supervised hierarchal cluster of 11 genes associated with decreases in transmembrane potential of mitochondria and apoptosis. These genes included p53, IL1 $\beta$ (interleukin 1 ), BCL2L11 (BCL2-like 11 , apoptosis facilitator protein), UCP2 and TGF $\beta 1$. Figure $4 \mathrm{C}$ shows a supervised cluster of 11 genes associated with 

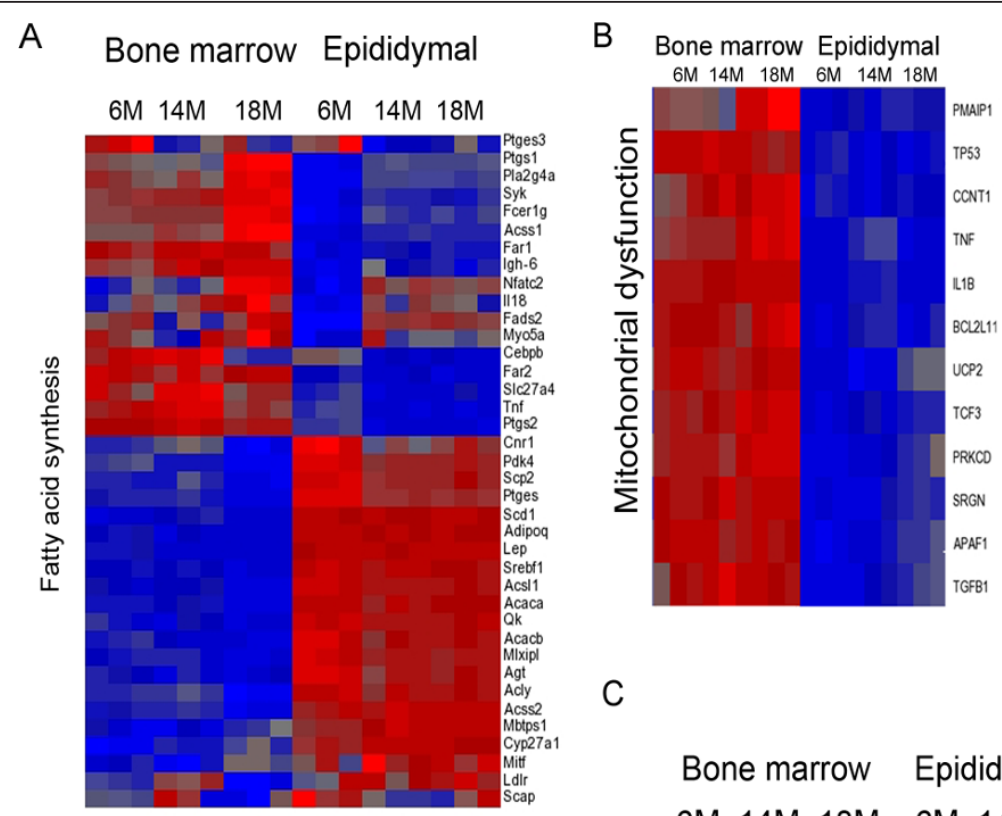

\section{C}

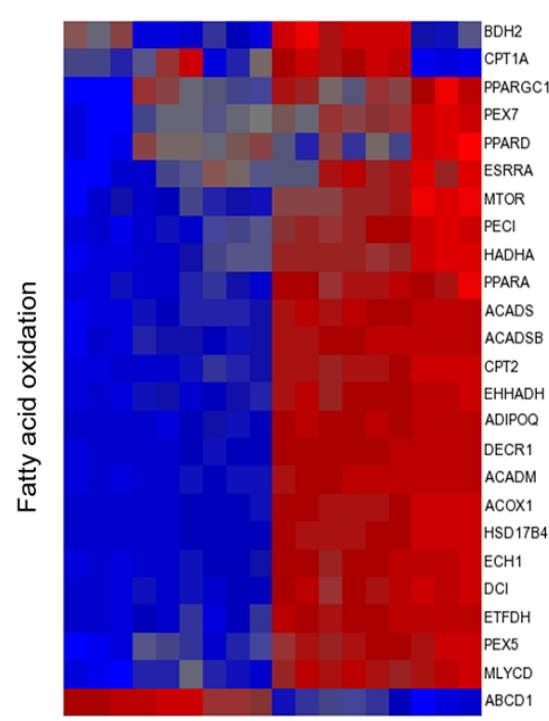

Bone marrow Epididymal

\section{$6 \mathrm{M} 14 \mathrm{M} 18 \mathrm{M} 6 \mathrm{M} 14 \mathrm{M} 18 \mathrm{M}$}

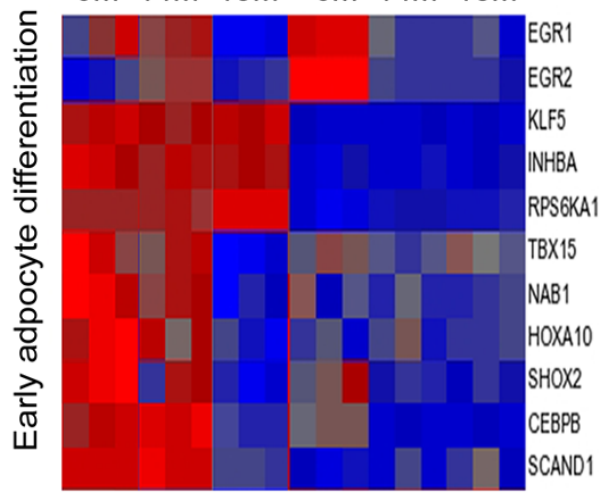

Figure 4 Heat maps of genes differentially expressed in bone marrow adipocytes. A. Clustering of genes involved in lipid metabolism (fatty acid synthesis, upper panel, and fatty acid oxidation, lower panel) with at least a 2-fold difference between bone marrow adipocytes compared with epididymal adipocytes. B. Clustering of genes involved in decreased transmembrane potential of mitochondria with at least a 2fold difference between bone marrow adipocytes compared with epididymal adipocytes. C. Clustering of genes involved in early adipocyte differentiation with at least a 2-fold difference between bone marrow adipocytes compared with epididymal adipocytes.

early adipocyte differentiation. These genes include EGR1 (early growth response 1, Krox-1), EGR2 (early growth response 2, Krox-20), KLF5 (Kruppel-like factor 5), INHBA (inhibin beta A, activin), CEBP/ $\beta$ and RPS6KA1 (ribosomal protein S6 kinase 1).

\section{Age-related alteration of gene expression in bone marrow and epididymal white adipocytes}

We next sought to identify genes affected by aging within each adipocyte population based on ontology. Aging- related alterations of gene expression were identified and a list of genes was generated yielding a total of 5649 genes that displayed significant changes in both bone marrow and epididymal adipocytes with age. Analyses were conducted using two-way ANOVA including interaction of cell types and age. The comparisons were conducted by comparing 14-month-old and 18-month-old to 6-month-old. Genes were further analyzed by Ingenuity Pathway Analyses to relate age-associated gene expression changes to biological function and signaling pathways. Age-related gene changes 
in adipocytes fell into several categories of biological function including inflammatory response, genetic disorder and cellular development, whereas the majority of alterations of genes in both adipocyte depots were associated with mitochondrial dysfunction and lipid metabolism. Figure 4A shows that genes involved in fatty acid synthesis were increased with age in bone marrow adipocytes, including Acss1 (acyl-coA synthetase short chain family 1), Fads2 (fatty acid desaturase 2), and Slc27a4 (fatty acid transporter 4). Heat maps of age-altered genes in the bone marrow and epididymal adipocytes are indicated in Figure 5. Figure 5A illustrates age-related changes in genes involved in mitochondria function in which 18-month-old bone marrow adipocytes and epididymal adipocytes were most affected. Figure 5B displays the differential expression of genes involved in lipolysis in response to aging in both adipocyte populations. TNF $\alpha$, Plin3 and Lipe (hormone sensitive lipase) increased in 14-month-old bone marrow adipocytes, whereas most of these genes decreased in 14-month-old epididymal adipocytes. PNPLA2 (ATGL) was decreased with age in both adipocyte depots. As shown in Table 4, pathways and networks associated with adipocyte differentiation, lipolysis and mitochondria function displayed significant changes with age in adipocytes. Approximately 60 percent of genes associated with adipocyte differentiation were significantly up-regulated in 14-month-old bone marrow adipocytes, whereas 70 percent of genes were downregulated in 14-month-old epididymal adipocytes. A similar pattern was also observed in lipolysis pathways. In addition, a group of genes associated with mitochondria function was significantly regulated in bone marrow adipocytes with age, but not in epididymal adipocytes, as indicated in Table 4. Fold change values of genes involved in adipocyte differentiation, lipolysis and mitochondrial function are listed in Tables 5, 6 and 7.

As indicated in Table 4, differential gene expression profiling was observed between bone marrow and epididymal adipocytes in pathway analysis. In order to examine the differences with age between bone marrow and epididymal adipocytes, we analyzed the fold changes with age in each adipocyte population separately. Table 8 shows the topregulated adipocyte genes in bone marrow adipocytes with age. This list indicates that adiponectin and IL6 were the most down-regulated genes, while TNF $\alpha$ and genes associated with fatty acid transport and lipolysis, such as CD36 and Lipe (hormone sensitive lipase, HSL), were upregulated. The increases in CD36 and HSL were not observed in epididymal adipocytes. On the other hand, Table 9 indicates that lipid droplet associated proteins Plin2 and Plin3 were significantly increased with age in epididymal white adipocytes, whereas Plin 3, but not Plin2, was significantly altered in bone marrow adipocytes. In addition, some adipocyte-specific genes (PPAR $\gamma$, Plin3 and CEBP $\beta$ ) increased in 14-month-old, then decreased in the 18-month-old group in bone marrow adipocytes, whereas they were not altered in the same direction in epididymal adipocytes (Tables 8 and 9).

Furthermore, in order to determine the most highly regulated adipocyte-specific genes in response to aging that are common to both adipocyte populations, we

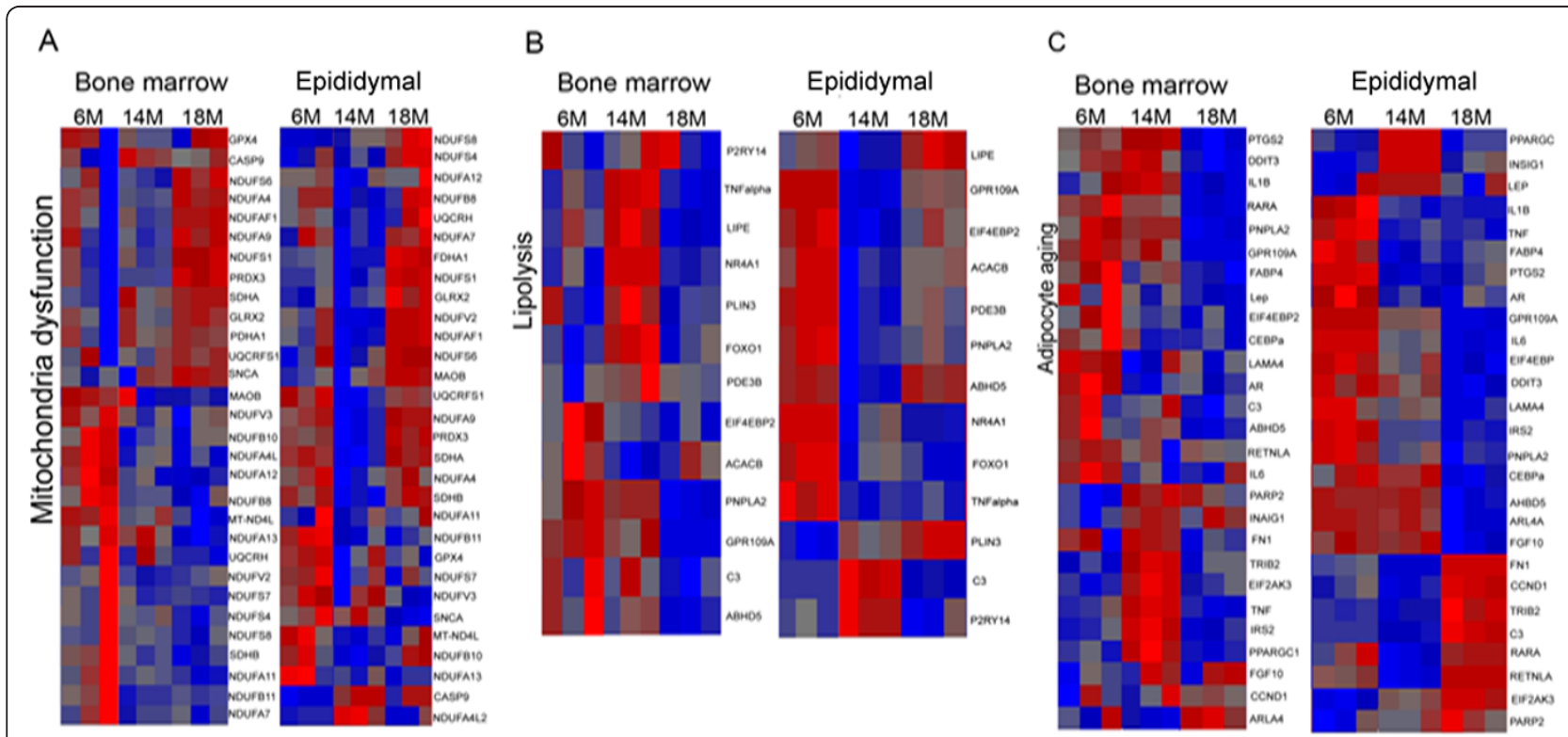

Figure 5 Age-related gene expression in adipocytes. Heat maps of age-associated gene expression changes in bone marrow and epididymal white adipocytes. A. Clustering of genes involved in mitochondria function. B. Clustering of genes associated with lipolysis. C. Clustering of ageregulated genes in bone marrow and epididymal adipocytes. 
Table 4 Top regulated pathways in bone marrow and epididymal adipocytes with age

\begin{tabular}{|c|c|c|c|c|c|c|c|}
\hline \multirow[b]{2}{*}{ Pathway } & \multirow[b]{2}{*}{ Cell type } & \multirow[b]{2}{*}{ Age (M) } & \multicolumn{2}{|c|}{ Genes } & \multicolumn{2}{|c|}{ Genes assigned } & \multirow[b]{2}{*}{$-\log 10(p \text { value })^{* *}$} \\
\hline & & & Up & Down & In pathway & Ratio* & \\
\hline \multirow[t]{4}{*}{ Adipocyte differentiation } & Bone marrow & $14 \mathrm{M}$ & 18 & 12 & 30 & 0.36 & 1.922 \\
\hline & & $18 \mathrm{M}$ & 11 & 19 & & 0.486 & 4.436 \\
\hline & Epididymal & $14 \mathrm{M}$ & 9 & 21 & 30 & 0.61 & 6.019 \\
\hline & & $18 \mathrm{M}$ & 8 & 22 & & 0.46 & 2.498 \\
\hline \multirow[t]{4}{*}{ Lipolysis } & Bone marrow & $14 \mathrm{M}$ & 6 & 7 & 13 & 0.289 & 1.347 \\
\hline & & $18 \mathrm{M}$ & 5 & 8 & & 0.263 & 0.87 \\
\hline & Epididymal & $14 \mathrm{M}$ & 2 & 11 & 13 & 0.342 & 1.203 \\
\hline & & $18 \mathrm{M}$ & 2 & 11 & & 0.289 & 0.659 \\
\hline \multirow[t]{4}{*}{ Mitochondria dysfunction } & Bone marrow & $14 \mathrm{M}$ & 12 & 18 & 30 & 0.237 & 1.115 \\
\hline & & $18 \mathrm{M}$ & 13 & 17 & & 0.323 & 3.364 \\
\hline & Epididymal & $14 \mathrm{M}$ & 3 & 27 & 30 & 0.24 & 0.487 \\
\hline & & $18 \mathrm{M}$ & 21 & 9 & & 0.226 & 0.28 \\
\hline
\end{tabular}

For each gene, the fold change of expression of 14-month-old (14M) and 18-month-old (18M) was calculated versus 6-month-old (6M). Pathways that have significant association with the whole set of regulated genes in bone marrow and epididymal adipocytes with age were assessed using IPA software. * Ratio of altered genes in bone marrow adipocytes to assigned pathway. ${ }^{* *}$ The p-value was calculated by IPA using Fisher's Exact Test. A threshold of 1.30 was selected $(p<0.05)$

Table 5 Age-associated fold changes in genes involved in adipocyte differentiation

\begin{tabular}{|c|c|c|c|c|c|}
\hline \multirow[b]{2}{*}{ Symbol } & \multirow[b]{2}{*}{ Entrez Gene Name } & \multicolumn{2}{|c|}{ Bone marrow } & \multicolumn{2}{|c|}{ Epididymal } \\
\hline & & $14 \mathrm{M}$ & $18 \mathrm{M}$ & $14 \mathrm{M}$ & $18 \mathrm{M}$ \\
\hline AR & androgen receptor & -1.84 & -2.03 & -1.47 & -1.82 \\
\hline ARL4A & ADP-ribosylation factor-like 4A & -1.34 & 1.28 & -2.04 & 1.03 \\
\hline CCND1 & cyclin D1 & 1.26 & 1.11 & 2.48 & -1.64 \\
\hline CEBPA & CCAAT/enhancer binding protein (C/EBP), alpha & -1.51 & -1.43 & -1.33 & 1.15 \\
\hline DDIT3 & DNA-damage-inducible transcript 3 & 1.22 & -2.14 & -1.76 & -1.16 \\
\hline EBF1 & early B-cell factor 1 & 1.43 & -1.50 & -1.28 & -1.41 \\
\hline EIF2AK3 & eukaryotic translation initiation factor 2-alpha kinase 3 & 1.80 & 1.17 & 1.70 & 1.53 \\
\hline FABP4 & fatty acid binding protein 4 , adipocyte & -1.54 & -2.57 & -1.23 & -1.32 \\
\hline FGF10 & fibroblast growth factor 10 & 1.23 & 1.18 & -2.60 & 1.04 \\
\hline FN1 & fibronectin 1 & 1.36 & -1.18 & 7.06 & -3.16 \\
\hline IL6 & interleukin 6 (interferon, beta 2) & -2.04 & -2.07 & -20.53 & -5.56 \\
\hline IL1B & interleukin 1, beta & 1.37 & -1.48 & -2.26 & -2.16 \\
\hline INSIG1 & insulin induced gene 1 & 1.26 & 1.49 & 1.33 & 2.81 \\
\hline IRS2 & insulin receptor substrate 2 & 1.96 & -1.13 & -4.26 & -2.94 \\
\hline LAMA4 & laminin, alpha 4 & -1.44 & -1.38 & -1.41 & -1.18 \\
\hline LEP & leptin & -2.02 & -1.77 & 1.01 & 1.59 \\
\hline LIF & leukemia inhibitory factor (cholinergic differentiation factor) & 1.88 & 1.11 & -1.03 & -1.07 \\
\hline NR3C1 & nuclear receptor subfamily 3, group C, member 1 (glucocorticoid receptor) & 1.29 & 1.02 & 1.01 & 1.15 \\
\hline PARP2 & poly (ADP-ribose) polymerase 2 & 1.35 & 1.24 & 1.30 & 1.21 \\
\hline PPARGC1A & peroxisome proliferator-activated receptor gamma, coactivator 1 alpha & 1.41 & -1.09 & -1.05 & 2.02 \\
\hline PTGS1 & prostaglandin-endoperoxide synthase 1 (prostaglandin G/H synthase and cyclooxygenase) & -1.34 & 1.03 & 3.29 & -1.59 \\
\hline PTGS2 & prostaglandin-endoperoxide synthase 2 (prostaglandin G/H synthase and cyclooxygenase) & 1.43 & -2.09 & -3.75 & -5.58 \\
\hline RARA & retinoic acid receptor, alpha & -1.30 & -2.35 & 1.06 & -1.49 \\
\hline RETNLA & resistin like alpha & -1.32 & -1.11 & 2.96 & -10.77 \\
\hline SCD & stearoyl-CoA desaturase (delta-9-desaturase) & 1.80 & 1.11 & 1.01 & 1.05 \\
\hline TNF & tumor necrosis factor & 2.36 & -1.48 & -2.37 & -2.18 \\
\hline TRIB2 & tribbles homolog 2 & 2.98 & 1.17 & 1.78 & -1.18 \\
\hline VDR & vitamin $D(1,25$ - dihydroxyvitamin D3) receptor & -1.39 & -1.32 & -1.12 & -1.21 \\
\hline
\end{tabular}

The list includes age-related fold change in genes involved in adipocytes differentiation in bone marrow and epididymal adipocytes. The set of regulated genes was selected according to the IPA knowledge-base. The 14-month (14M) and 18-month-old (18M) were compared to 6-month-old. The significance of differences was measured by two-way ANOVA. The significance of differences was estimated by a Benjamini-Hochberg corrected $p$ value $(p<0.01)$. 
Table 6 Age-related fold changes in genes involved in lipolysis

\begin{tabular}{|c|c|c|c|c|c|}
\hline \multirow[b]{2}{*}{ Symbol } & \multirow[b]{2}{*}{ Entrez Gene Name } & \multicolumn{2}{|c|}{ Bone marrow } & \multicolumn{2}{|c|}{ Epididymal } \\
\hline & & $14 \mathrm{M}$ & $18 \mathrm{M}$ & $14 \mathrm{M}$ & $18 \mathrm{M}$ \\
\hline ABHD5 & $\alpha \beta$ hydrolase domain containing 5 & -1.12 & -1.26 & -1.97 & 1.04 \\
\hline ACACB & acetyl-CoA carboxylase beta & -1.40 & -1.14 & -2.22 & -1.31 \\
\hline ADRB2 & adrenergic, beta-2-, receptor, surface & 1.22 & 1.49 & -1.37 & -2.04 \\
\hline C3 & complement component 3 & -1.07 & -1.23 & 2.16 & -1.11 \\
\hline EIF4EBP2 & eukaryotic translation initiation factor $4 \mathrm{E}$ binding protein 2 & -1.38 & -1.53 & -1.60 & -1.15 \\
\hline FOXO1 & forkhead box $\mathrm{O} 1$ & 1.99 & 1.17 & -1.42 & -1.44 \\
\hline GPR109A & G protein-coupled receptor 109A & -1.29 & -3.99 & -10.52 & -2.20 \\
\hline NR4A1 & nuclear receptor subfamily 4 , group A, member 1 & 2.53 & 1.11 & -4.03 & -4.62 \\
\hline P2RY14 & purinergic receptor P2Y, G-protein coupled, 14 & 1.07 & 1.05 & 1.54 & -1.21 \\
\hline PDE3B & phosphodiesterase 3B, cGMP-inhibited & 1.57 & 1.25 & -1.99 & -1.32 \\
\hline PLIN1 & perilipin 1 & -1.24 & -1.21 & -1.36 & 1.04 \\
\hline PNPLA2 & patatin-like phospholipase domain containing 2 & -1.03 & -1.43 & -1.39 & -1.21 \\
\hline TNF & tumor necrosis factor & 2.37 & -1.38 & -2.36 & -2.12 \\
\hline
\end{tabular}

The list includes age-related fold change in genes involved in lipolysis in bone marrow and epididymal adipocytes. The set of regulated genes was selected according to the IPA knowledge-base. The 14-month (14M) and 18-month-old (18M) were compared to 6-month-old. The significance of differences was measured by two-way ANOVA. The significance of differences was estimated by a Benjamini-Hochberg corrected $p$ value $(p<0.01)$.

identified 27 genes in which expression levels were significantly altered with age in both adipocytes using a threeway ANOVA model with $p<0.05$ in the interaction of age and cell types, as shown in Figure 5C and Table 10. A heat map of age-altered adipocyte genes (Figure $5 \mathrm{C}$ ) reveals that 19 of 27 genes (70\%) were regulated in the same direction with age in both adipocyte populations. These genes include EIF2AK3 (eukaryotic translation initiation factor 2-alpha kinase 3), FN1 (fibronectin 1), INSIG1 (insulin induced gene 1), PNPLA2, ABHD5, GPR109A, FABP4 and IL6 (Table 10). The other 8 genes were regulated with age in both adipocyte populations, but their patterns of regulation differed between bone marrow and epididymal adipocytes. Interestingly, the list indicates that IL6 (interleukin 6) was the most down-regulated gene with age in 14-month-old bone marrow and epididymal adipocytes, and GPR 109A (G protein-coupled receptor 109A) was significantly decreased 4.5 fold in 18 -monthold bone marrow and reduced 10.6 fold in 14-monthold epididymal adipocytes compared to 6-month-old (Table 10).

\section{Discussion}

Obesity accelerates the progression of aging and agerelated metabolic disorders such as insulin resistance and type 2 diabetes [22,23]. The contribution of the heterogeneity of adipocytes to aging and age-related metabolic syndrome has been studied in subcutaneous and visceral adipose tissue $[1,4]$. Adipocytes and osteoblasts originate from MSCs within the bone marrow, where there is a reciprocal relationship in the development along each lineage [5-7]. During aging, increased bone marrow adipogenesis compromises hematopoietic stem cell differentiation and bone remodeling [24]. This study represents the first attempt to characterize primary bone marrow adipocytes by gene profiling and to compare their gene profiles with epididymal white adipocytes in response to aging. We observed a significant increase in fat infiltration in the bone marrow in 14-month-old male mice, which was accompanied by an increase in circulating insulin and a decrease in osteocalcin levels, reflecting some of the metabolic changes that occur with age.

\section{Differential gene profiling of bone marrow adipocytes}

Microarray analysis of gene expression by gene ontologies and functional pathways allowed us not only to identify genes differentially expressed in bone marrow adipocytes, but also genes whose expressions were significantly altered during aging. Recently, Majka et al performed a microarray analysis of bone marrow progenitor-derived adipocytes which were purified from peripheral adipose depots of transplanted recipient mice by flow cytometry [20]. Their characterization showed that bone marrow progenitorderived adipocytes are different from conventional white adipocytes with low expression levels of leptin, mitochondrial and peroxisomal capacity and high expression of inflammatory genes. The study design was different from the current study because their study examined bone marrow progenitor-derived adipocytes isolated from visceral or subcutaneous depots, whereas our study examined primary adipocytes isolated directly from bone marrow. Even with this major difference in design, our results with primary bone marrow adipocytes directly isolated from the bone marrow of aging mice agree remarkably well with their results. Global array analysis by PCA (Principal component analysis) mapping showed a clear separation between bone marrow and epididymal adipocytes. Previous studies have shown that macrophages express 
Table 7 Age-related fold changes in genes involved in mitochondrial function

\begin{tabular}{|c|c|c|c|c|c|}
\hline \multirow[b]{2}{*}{ Symbol } & \multirow[b]{2}{*}{ Entrez Gene Name } & \multicolumn{2}{|c|}{$\begin{array}{c}\text { Bone } \\
\text { marrow }\end{array}$} & \multicolumn{2}{|c|}{ Epididymal } \\
\hline & & $14 \mathrm{M}$ & $18 \mathrm{M}$ & $14 \mathrm{M}$ & $18 \mathrm{M}$ \\
\hline CASP9 & caspase 9 , apoptosis-related cysteine peptidase & 1.51 & 1.38 & 1.27 & 1.23 \\
\hline GLRX2 & glutaredoxin 2 & 1.36 & 1.79 & -1.05 & 1.38 \\
\hline GPX4 & glutathione peroxidase 4 (phospholipid hydroperoxidase) & 1.08 & 1.30 & -1.12 & -1.11 \\
\hline MAOB & monoamine oxidase B & -1.23 & -1.39 & -1.06 & 1.31 \\
\hline MT-ND4L & NADH dehydrogenase, subunit 4L (complex I) & -1.25 & -1.63 & -1.22 & -1.17 \\
\hline NDUFA4 & NADH dehydrogenase (ubiquinone) 1 alpha subcomplex, 4, 9 kDa & 1.11 & 1.81 & -1.21 & 1.00 \\
\hline NDUFA7 & NADH dehydrogenase (ubiquinone) 1 alpha subcomplex, 7, 14.5 kDa & -1.72 & -1.69 & -1.15 & 1.12 \\
\hline NDUFA11 & NADH dehydrogenase (ubiquinone) 1 alpha subcomplex, 11, $14.7 \mathrm{kDa}$ & -1.46 & -1.68 & -1.07 & 1.04 \\
\hline NDUFA12 & NADH dehydrogenase (ubiquinone) 1 alpha subcomplex, 12 & -1.58 & -1.71 & -1.11 & 1.09 \\
\hline NDUFA13 & NADH dehydrogenase (ubiquinone) 1 alpha subcomplex, 13 & -1.05 & -1.33 & -1.26 & -1.30 \\
\hline NDUFA4L2 & NADH dehydrogenase (ubiquinone) 1 alpha subcomplex, 4-like 2 & -1.26 & -1.38 & 1.50 & 1.05 \\
\hline NDUFA9 (includes EG:4704) & NADH dehydrogenase (ubiquinone) 1 alpha subcomplex, 9, $39 \mathrm{kDa}$ & 1.11 & 1.77 & -1.46 & 1.10 \\
\hline NDUFAF1 & NADH dehydrogenase (ubiquinone) 1 alpha subcomplex, assembly factor 1 & 1.18 & 1.87 & -1.41 & 1.42 \\
\hline NDUFB8 & NADH dehydrogenase (ubiquinone) 1 beta subcomplex, 8, 19 kDa & -1.31 & -1.40 & -1.35 & 1.09 \\
\hline NDUFB10 & NADH dehydrogenase (ubiquinone) 1 beta subcomplex, 10, 22 kDa & -1.46 & -1.38 & -1.18 & 1.01 \\
\hline NDUFB11 & NADH dehydrogenase (ubiquinone) 1 beta subcomplex, 11, $17.3 \mathrm{kDa}$ & -1.58 & -1.38 & -1.18 & -1.13 \\
\hline NDUFS1 & NADH dehydrogenase (ubiquinone) Fe-S protein 1, $75 \mathrm{kDa}$ (NADH-coenzyme $\mathrm{Q}$ reductase) & 1.29 & 2.22 & -1.21 & 1.67 \\
\hline NDUFS4 & NADH dehydrogenase (ubiquinone) Fe-S protein 4, $18 \mathrm{kDa}$ (NADH-coenzyme $\mathrm{Q}$ reductase) & -1.22 & -1.39 & -1.03 & 1.48 \\
\hline NDUFS7 & NADH dehydrogenase (ubiquinone) Fe-S protein 7, $20 \mathrm{kDa}$ (NADH-coenzyme $\mathrm{Q}$ reductase) & -1.53 & -1.51 & -1.16 & -1.08 \\
\hline NDUFS8 & NADH dehydrogenase (ubiquinone) Fe-S protein 8, $23 \mathrm{kDa}$ (NADH-coenzyme $\mathrm{Q}$ reductase) & -1.37 & -1.52 & 1.14 & 1.46 \\
\hline NDUFS6 (includes EG:4726) & NADH dehydrogenase (ubiquinone) Fe-S protein 6, $13 \mathrm{kDa}$ (NADH-coenzyme Q reductase) & 1.01 & 1.68 & -1.08 & 1.29 \\
\hline NDUFV2 & $\mathrm{NADH}$ dehydrogenase (ubiquinone) flavoprotein 2, $24 \mathrm{kDa}$ & -1.54 & -1.31 & -1.27 & 1.26 \\
\hline NDUFV3 & $\mathrm{NADH}$ dehydrogenase (ubiquinone) flavoprotein 3, $10 \mathrm{kDa}$ & -1.24 & -1.38 & -1.11 & -1.12 \\
\hline PDHA1 (includes EG:5160) & pyruvate dehydrogenase (lipoamide) alpha 1 & 1.62 & 1.85 & -1.20 & 1.45 \\
\hline PRDX3 & peroxiredoxin 3 & 1.19 & 2.39 & -1.42 & 1.19 \\
\hline SDHA & succinate dehydrogenase complex, subunit A, flavoprotein (Fp) & 1.31 & 1.51 & -1.35 & 1.06 \\
\hline $\mathrm{SDHB}$ & succinate dehydrogenase complex, subunit B, iron sulfur (Ip) & -1.25 & -1.31 & -1.35 & 1.10 \\
\hline SNCA & synuclein, alpha (non A4 component of amyloid precursor) & -1.08 & 1.67 & -1.16 & -3.22 \\
\hline UQCRFS1 & ubiquinol-cytochrome c reductase, Rieske iron-sulfur polypeptide 1 & 1.20 & 1.49 & -1.68 & -1.05 \\
\hline UQCRH & ubiquinol-cytochrome c reductase hinge protein & -1.14 & -1.32 & -1.27 & 1.24 \\
\hline
\end{tabular}

The list includes the mitochondrial genes that change with age in bone marrow and epididymal adipocytes. The set of regulated genes was selected on the basis of their expression in adipose cells according to the IPA knowledge-base. For each gene, the fold change value in gene expression was calculated between mean values in bone marrow adipocytes. The 14-month (14M) and 18-month-old (18M) were compared to 6-month-old. The significance of differences was measured by two-way ANOVA.

several genes classically associated with adipocytes, such as FABP4, Plin1 and PPAR $\gamma$ [25]; yet there are distinctions between adipocytes and macrophages. For instance, adipocytes do not express the macrophage specific cell surface marker CD11b (Mac-1 $\alpha$ ), while macrophages do not express adiponectin [26]. The primary adipocytes isolated from the bone marrow in our studies are characterized by low CD11b expression and high adiponectin (>3-fold) expression as confirmed by quantitative PCR. Expression levels of adipocyte-specific genes (Plin1, FABP4, leptin and Plin2) were also higher in the isolated bone marrow adipocytes than bone marrow stromal cells, thus confirming that the populations of cells studied are adipocytes. CD11b staining also confirmed that there were similar degrees of contamination of adipocytes by monocyte/ macrophages in preparations from bone marrow and epididymal adipocytes. In our study, adipocyte specific genes (PPAR $\gamma$, FABP4, Plin1, adipsin and leptin) were expressed at significantly lower levels in bone marrow adipocytes compared with epididymal white adipocytes, whereas the expression levels of inflammatory genes such as IL-6 and TNF $\alpha$ were found to be higher in bone marrow adipocytes compared with epididymal white adipocytes. The increased expression of proinflammatory cytokines in bone marrow adipocytes might be associated with a high level of macrophage infiltration within the aged bone marrow environment; however, as mentioned, we did not detect significant differences in macrophage contamination of the adipocyte preparations isolated from bone marrow versus epididymal depots. Interestingly, while leptin 
Table 8 Top regulated adipocyte genes in bone marrow adipocytes with age

\begin{tabular}{|c|c|c|c|c|}
\hline Symbol & Entrez Gene Name & $14 \mathrm{M}$ & $18 \mathrm{M}$ & $p$-value (cell type*age) \\
\hline TNF $\alpha$ & tumor necrosis factor $\alpha$ & 2.37 & -1.38 & $1.47 \mathrm{E}-05$ \\
\hline FOXO1 & forkhead box $\mathrm{O} 1$ & 1.99 & 1.17 & 0.0006 \\
\hline IRS2 & insulin receptor substrate 2 & 1.93 & -1.08 & 0.0008 \\
\hline C/EBP $\beta$ & CCAAT/enhancer binding protein beta & 1.79 & -1.23 & $1.22 \mathrm{E}-05$ \\
\hline CD36 & fatty acid translocase & 1.38 & 2.00 & 0.001 \\
\hline PPAR $\gamma$ & peroxisome proliferator-activated receptor gamma & 1.36 & 1.08 & 0.003 \\
\hline PLIN3 & perilipin 3, TIP47 & 1.25 & 1.04 & 0.007 \\
\hline SOD2 & superoxide dismutase 2, mitochondrial & 1.24 & -1.09 & 0.001 \\
\hline UCP2 & uncoupling protein 2 & 1.24 & 1.18 & $8.1 \mathrm{E}-06$ \\
\hline LIPE & lipase, hormone sensitive & 1.23 & -1.27 & $2.1 \mathrm{E}-05$ \\
\hline SERPINE1 & plasminogen activator inhibitor type 1 & 1.21 & -1.30 & 0.0004 \\
\hline GPX1 & glutathione peroxidase 1 & 1.04 & 1.23 & 0.0002 \\
\hline SLC2A4 & GLUT-4 & -1.11 & 1.30 & 0.04 \\
\hline CFD & adipsin & -1.12 & 1.25 & 0.002 \\
\hline FABP4 & fatty acid binding protein 4 , adipocyte & -1.52 & -2.46 & 0.001 \\
\hline PTPN11 & protein tyrosine11 & -1.58 & -1.21 & 0.0006 \\
\hline ADIPOR2 & adiponectin receptor 2 & -1.66 & -1.44 & 0.001 \\
\hline LEPR & leptin receptor & -1.94 & 1.44 & 0.002 \\
\hline IL6 & interleukin 6 (interferon, beta 2) & -2.19 & -1.91 & $8.34 \mathrm{E}-05$ \\
\hline ADIPOQ & adiponectin & -2.25 & -1.88 & 0.01 \\
\hline
\end{tabular}

The list includes the adipocyte genes that change with age in bone marrow adipocytes. The set of regulated genes was selected on the basis of their expression in adipose according to the IPA knowledge-base. For each gene, the fold change value in gene expression was calculated between mean values in bone marrow adipocytes from mice. The 14-month (14M) and 18-month-old (18M) were compared to 6-month-old. The significance of differences was measured by two-way ANOVA.

was expressed at a relatively lower level in bone marrow adipocytes than in epididymal adipocytes, the leptin receptor (LEPR) was more highly expressed in bone marrow adipocytes. In addition, expression of genes involved in fatty acid synthesis and fatty acid oxidation were lower in bone marrow compared with epididymal adipocytes, whereas genes associated with decreased mitochondrial function, such as TNF $\alpha$, p53, BCL2L11 and IL-1 $\beta$, were significantly higher in bone marrow compared with epididymal adipocytes. Furthermore, we observed that the

Table 9 Top regulated adipocyte genes in epididymal adipocytes with age

\begin{tabular}{|c|c|c|c|c|}
\hline & Entrez Gene Name & $14 \mathrm{M}$ & $18 \mathrm{M}$ & $P$ value (cell type*age) \\
\hline UCP2 & uncoupling protein 2 & 2.3 & 1.3 & 8.1E-061 \\
\hline LEPR & leptin receptor & 1.3 & -1.1 & 0.02 \\
\hline FGFR1 & fibroblast growth factor receptor 1 & 1.3 & -1.5 & 0.03 \\
\hline PLIN3 & perilipin 3, TIP47 & 1.2 & 1.6 & 0.0007 \\
\hline PPAR $\gamma$ & peroxisome proliferator-activated receptor gamma & 1.1 & 1.8 & 0.0003 \\
\hline PLIN2 & Perilipin 2, adipophilin, ADFP & 1 & 1.7 & $5.8 \mathrm{E}-05$ \\
\hline ADIPOQ & Adiponectin & -1.2 & 1.2 & 0.01 \\
\hline FABP4 & fatty acid binding protein 4, adipocyte & -1.2 & -1.3 & 0.05 \\
\hline $\mathrm{C} / \mathrm{EBP} \alpha$ & CCAAT/enhancer binding protein, alpha & -1.3 & 1.1 & 0.01 \\
\hline PPARGC $1 \alpha$ & peroxisome proliferator-activated receptor gamma, coactivator 1 alpha & -1.5 & 2 & $1.4 \mathrm{E}-05$ \\
\hline ADIPOR2 & adiponectin receptor 2 & -1.6 & -1.1 & 0.001 \\
\hline SOD2 & superoxide dismutase 2, mitochondrial & -1.8 & -1.1 & 0.0001 \\
\hline $\mathrm{TNF} \alpha$ & $\mathrm{TNF} \alpha$ & -2.3 & -2.1 & 0.0001 \\
\hline C/EBP $\beta$ & CCAAT/enhancer binding protein, beta & -2.4 & -1 & $1.4 \mathrm{E}-05$ \\
\hline IRS2 & insulin receptor substrate 2 & -4.3 & -2.8 & $1.2 \mathrm{E}-05$ \\
\hline SERPINE1 & plasminogen activator inhibitor type 1 & -7.3 & -4.3 & 0.0004 \\
\hline IL6 & interleukin 6 & -19.8 & -4.8 & 8.3E-05 \\
\hline
\end{tabular}

The list includes the adipocyte genes that change with age in epididymal adipocytes. The set of regulated genes was selected on the basis of their expression in adipose according to the IPA knowledge-base. For each gene, the fold change value in gene expression was calculated between mean values in epididymal adipocytes. The 14-month (14M) and 18-month-old (18M) were compared to 6-month-old. The significance of differences was measured by two-way ANOVA. 
Table 10 Age-regulated adipocyte gene expression

\begin{tabular}{|c|c|c|c|c|c|c|}
\hline \multirow[b]{2}{*}{ Symbol } & \multirow[b]{2}{*}{ Entrez Gene Name } & \multicolumn{2}{|c|}{ Bone marrow } & \multicolumn{2}{|c|}{ Epididymal } & \multirow{2}{*}{ - $p$-value (Age } \\
\hline & & $14 \mathrm{M}$ & $18 \mathrm{M}$ & $14 \mathrm{M}$ & $18 \mathrm{M}$ & \\
\hline TRIB2 & tribbles homolog 2 (Drosophila) & 3.0 & 1.2 & 1.8 & -1.2 & $1.78 \mathrm{E}-05$ \\
\hline TNF $\alpha$ & tumor necrosis factor $\alpha$ & 2.4 & -1.5 & -2.4 & -2.2 & 0.00013 \\
\hline IRS2 & insulin receptor substrate 2 & 2.0 & -1.1 & -4.3 & -2.9 & 0.00018 \\
\hline EIF2AK3 & eukaryotic translation initiation factor 2-alpha kinase 3 & 1.8 & 1.2 & 1.7 & 1.5 & $2.12 \mathrm{E}-06$ \\
\hline PTGS2 & prostaglandin-endoperoxide synthase 2 (prostaglandin G/H synthase and cyclooxygenase) & 1.4 & -2.1 & -3.8 & -5.6 & 4.87E-07 \\
\hline PPARGC1 $\alpha$ & peroxisome proliferator-activated receptor gamma, coactivator 1 alpha & 1.4 & -1.1 & -1.0 & 2.0 & 0.0024 \\
\hline IL $1 \beta$ & interleukin 1, beta & 1.4 & -1.5 & -2.3 & -2.2 & 0.00026 \\
\hline FN1 & fibronectin 1 & 1.4 & -1.2 & 7.1 & -3.2 & 4.20E-07 \\
\hline PARP2 & poly (ADP-ribose) polymerase 2 & 1.4 & 1.2 & 1.3 & 1.2 & 0.0018 \\
\hline CCND1 & cyclin D1 & 1.3 & 1.1 & 2.5 & -1.6 & 0.00062 \\
\hline INSIG1 & insulin induced gene 1 & 1.3 & 1.5 & 1.3 & 2.8 & 0.0057 \\
\hline FGF10 & fibroblast growth factor 10 & 1.2 & 1.2 & -2.6 & 1.0 & 0.0031 \\
\hline DDIT3 & DNA-damage-inducible transcript 3 & 1.2 & -2.1 & -1.8 & -1.2 & 0.0036 \\
\hline C3 & complement component 3 & 1.0 & -1.4 & 2.1 & -1.3 & 0.00052 \\
\hline PNPLA2 & patatin-like phospholipase domain containing 2 & -1.0 & -1.6 & -1.4 & -1.2 & 0.0049 \\
\hline ABHD5 & $\alpha \beta$ hydrolase domain containing 5 & -1.0 & -1.4 & -2.0 & -1.1 & 0.00059 \\
\hline GPR109A & G protein-coupled receptor 109A & -1.2 & -4.5 & -10.6 & -2.7 & $2.68 \mathrm{E}-08$ \\
\hline RAR $\alpha$ & retinoic acid receptor, alpha & -1.3 & -2.4 & 1.1 & -1.5 & $3.42 \mathrm{E}-05$ \\
\hline RETNL $\alpha$ & resistin like alpha & -1.3 & -1.1 & 3.0 & -10.8 & $8.46 \mathrm{E}-08$ \\
\hline ARL4A & ADP-ribosylation factor-like 4A & -1.3 & 1.3 & -2.0 & 1.0 & $3.30 \mathrm{E}-05$ \\
\hline EIF4EBP2 & eukaryotic translation initiation factor $4 \mathrm{E}$ binding protein 2 & -1.4 & -1.6 & -1.6 & -1.2 & 0.0024 \\
\hline LAMA4 & laminin, alpha 4 & -1.4 & -1.4 & -1.4 & -1.2 & 0.0065 \\
\hline C/EBP $\alpha$ & CCAAT/enhancer binding protein, alpha & -1.5 & -1.4 & -1.3 & 1.1 & 0.0062 \\
\hline FABP4 & fatty acid binding protein 4 , adipocyte & -1.5 & -2.6 & -1.2 & -1.3 & 0.0026 \\
\hline AR & androgen receptor & -1.8 & -2.0 & -1.5 & -1.8 & 0.00026 \\
\hline LEP & leptin & -2.0 & -1.8 & 1.0 & 1.6 & 0.0017 \\
\hline IL6 & interleukin 6 & -2.0 & -2.1 & -20.5 & -5.6 & $8.65 \mathrm{E}-07$ \\
\hline
\end{tabular}

The list includes the genes that change with age in both bone marrow and epididymal adipocytes. The set of the 27 regulated genes was selected on the basis of their fold changes across age in both adipocyte populations sorted using Partek Genome Suit software and IPA. The significance of differences was measured by two-way ANOVA. A low value in $p$ indicates the gene is differentially expressed with respect to age. The comparison included 14-month (14M) and 18-monthold (18M) compared to 6-month-old.

expression of a group of genes associated with early adipocyte differentiation, including CEBP/ $\beta, \mathrm{KLF} 4$ and EGR1\&2, INHBA and S6K1, were higher in bone marrow adipocytes than epididymal adipocytes [27-29], indicating that bone marrow adipocytes are in an early stage of adipocyte differentiation. This observation also is supported by low expression of Plin 1 and relatively higher expression of Plin2 in bone marrow adipocytes (14-month-old), as Plin2 is expressed early in adipocyte differentiation [30]. Previous studies also indicated that fat cell progenitors, preadipocytes, resemble the phenotype of macrophages. Preadipocytes account for 15 to $50 \%$ of cells in fat tissues [31]. Aging increases the numbers of preadipocytes and the production of cytokines PAI, IL-6 and other proinflammatory cytokines $[1,32]$. Thus, it is possible that the presence of newly differentiated adipocytes and fat cell progenitor cells might contribute to the differential expression patterns observed in bone marrow adipocytes.

\section{Age-related gene changes in bone marrow and} epididymal adipocytes

Aging is characterized by fat redistribution with increased visceral fat and relative loss of subcutaneous fat in humans [22]. Microarray analysis of age-related gene expression in white adipose tissue (WAT) has been reported in rodents $[33,34]$. Linford et al reported that aging had a significant effect on gene expression in adipose tissues, particularly genes involved in PPAR $\gamma$-dependent adipogenesis and lipid metabolism declined with age. Others have suggested that expression levels of key adipogenic transcription factors, $\mathrm{C} / \mathrm{EBP} \alpha, \mathrm{C} / \mathrm{EBP} \delta$ and PPAR $\gamma$, are lower in differentiating adipocytes isolated from old compared to young rats [35]. Here we observed a differential expression between bone marrow and epididymal white adipocytes with age. While PPAR $\gamma$ and C/EBP $\beta$ significantly increased in 14-month-old then decreased or did not change in 18month-old bone marrow adipocytes, PPAR $\gamma$ increased and 
C/EBP $\beta$ decreased at 14 and 18 months in epididymal adipocytes. Global analysis of pathways associated with adipogenesis and lipolysis showed that expressions of genes within these pathways are generally increased in 14-month-old bone marrow adipocytes, whereas they are generally decreased in epididymal adipocytes. The observation that the expression pattern of some genes appears to be most highly affected at 14 months is possibly related to changes in body weight and fat mass, as body weights were highest at 14-months (Table 1) and declined at 18 months $(36.5 \pm 1.6 \mathrm{gm})$. Moreover, it is possible that age might have an even greater impact on differences in gene expression patterns if older animals (24 or 30 months) were examined.

A decrease in mitochondria function is associated with aging in heart, muscle, liver and white adipocytes in animals [36-39]. A decline in mitochondria function is highly associated with an increase in inflammation and apoptosis $[40,41]$. Linford et al reported that the most highly induced gene changes in adipose tissue and heart with aging in rats are genes associated with inflammation [33]. Our data are in agreement with previous reports demonstrating an increase in inflammatory genes in both adipocyte populations with age, and in particular in the bone marrow, since the pathway analysis indicated that there were more genes altered with age in bone marrow adipocytes. We further examined whether the genes known to be involved in aging were altered in adipocytes. For examples, SOD2 (superoxide dismutase 2) and Sirt1 (sirtuin 1), which are associated with mitochondrial aging [42], were significantly decreased in epididymal adipocytes with age, whereas these changes were not seen in bone marrow adipocytes. However, overall there was generally a similar expression pattern observed in both bone marrow and epididymal adipocytes in response to aging, but age has a greater impact on global gene expression in epididymal than in bone marrow adipocytes.

\section{Potential functional implications of gene expression profile of bone marrow adipocytes}

In view of the physical proximity of adipocytes and osteoblasts within the bone marrow and the inverse relationship between bone mass and bone marrow adiposity, it seems reasonable to speculate that adipocytes can directly influence bone remodeling. Indeed, we have shown that adipocytes can modulate key metabolic functions of osteoblasts in co-culture through the release of secretory products (50). Daley et al suggest that adipocyte-secreted cytokines TNF $\alpha$ and adiponectin inhibit hematopoietic progenitor cell expansion within the bone marrow and also affect bone remodeling [26]. In this regard it is noteworthy that Wdnm1-like, an adipocytesecreted protein, is expressed 3-4 fold higher in bone marrow adipocytes. Smas et al reported that Wdnm1-like is selectively expressed in adipose and liver and increases matrix metalloproteinase 2 (MMP2) activity [43]. It is possible that bone marrow adipocytes, through the release of Wdnm1-like, might contribute to extracellular remodeling within the bone marrow and mediate crosstalk between adipocytes, mesenchymal and hematopoietic stem cells. In addition to Wdnm1-like protein, we identified a number of genes that could potentially affect adipose-derived signaling to bone and whose expressions are increased in bone marrow adipocytes. For instance, the expression levels of oncostatin M (OM), SFRP4, ABCB4, TNF $\alpha$, TGF $\beta 1$, GPR109A and IL-6 are markedly increased in bone marrow adipocytes. Whereas the actions of cytokines, such as OM, TNF $\alpha$, and IL-6, and growth factors, such as TGF $\beta 1$, on bone are well described $[44,45]$, SFRP4 is a phosphatonin that inhibits both tubular phosphate reabsorption and Wnt signaling, and whose expression has been reported to increase during adipose differentiation of MSCs and to be associated with lower bone density in mice [46-48]. Moreover, transgenic expression of SFRP4 in osteoblasts results in lower bone density [49]. ABCB4, also known as multidrug resistance P-glycoprotein 3, translocates phosphatidylcholine $(\mathrm{PC})$ from the inner to the outer plasma membrane, thus functioning as a PC flippase; mutations in ABCB4 cause cholestatic liver disease [50]. Though no specific associations of ABCB4 with bone abnormalities are known, it is possible that adipocyte-derived PC might be supplied to and influence differentiation of MSCs or osteoblasts. GPR109A is the receptor for nicotinic acid, whose endogenous ligand appears to be a product of fatty acid oxidation, $\beta$-hydroxybutyrate [51]. This would reduce the local release of possible PPAR $\gamma$ or other receptor ligands or pro-ligands and potentially have a beneficial impact on bone. Therefore, the gene expression profile of bone marrow adipocytes is such that it could lead to both positive and negative effects on bone. The gene expression profile observed in 14-month-old bone marrow adipocytes was accompanied by elevated circulating serum insulin, glucose, adipocytokines (leptin, adiponectin) and reduced osteocalcin. The regulation of osteocalcin secretion by insulin has been shown in recent studies [16]. Therefore, it is possible that the increase in adipogenesis in the bone marrow of 14-month-old mice induces a negative influence on MSC lineages, thereby leading to a decline in osteoblast function, which could, in part, be attributed to hyperinsulinemia.

\section{Conclusions}

Taken together, comparison of gene expression profiles in bone marrow adipocytes with epididymal adipocytes indicates that bone marrow adipocytes express adipocyte-specific genes, but appear to have a gene expression pattern that distinguishes them from epididymal 
adipocytes. Primary adipocytes within the bone marrow are characterized by low expression levels of adipocytespecific genes and high levels of genes associated with early adipocyte lineage. However, adipocytes from both depots display common pathways and generally similar alterations in gene expression in response to aging. In depth research into the functional role of bone marrow adipocytes will be important for uncovering age related changes in bone, hematopoiesis and metabolic functions.

\section{Methods}

\section{Experimental animals and isolation of adipocytes}

Bone marrow adipocytes and epididymal white adipocytes ( $\mathrm{n}=6-10$ animals per group) were isolated from male C57BL/6J mice (6-months, 14-months and 18-months of age). All mice were housed in temperature-controlled conditions on a 12-h light, 12-h dark cycle, and were fed standard chow. All procedures were in accordance with institution guidelines and approved by the institutional animal care and use committee of the VA Palo Alto Health Care System. Briefly, both femurs and tibias were collected after mice were sacrificed. Bones were cleaned and rinsed with $75 \%$ ethanol and DEPC water to eliminate surrounding fat and muscle cells. Fresh bone marrows were flushed out with PBS containing $1 \%$ fatty acid-free BSA and $1 \%$ RNAase and DNAase-free water using a 25gauge needle from femurs and tibias. Red blood cells were lysed using red cell lysis buffer. After centrifugation at $3000 \mathrm{rpm}$ for $5 \mathrm{~min}$, floating adipocytes were collected from bone marrow stromal cells and then were washed with PBS buffer three times. In addition to the bone marrow, primary adipocytes were isolated from epididymal white adipose tissue (WAT) as described previously [52]. Briefly, epididymal WAT was removed from mice and minced with scissors into $2 \mathrm{ml}$ Kreb-Ringer HEPES buffer supplemented with 3\% BSA. Tissues were digested with collagenase type $\mathrm{I}(1 \mathrm{mg} / \mathrm{ml})$ for $40 \mathrm{~min}$ at $37^{\circ} \mathrm{C}$ in a 250 rpm shaker and adipocytes then isolated by flotation.

\section{Histology}

Distal femurs isolated from 6-month-old and 14-monthold C57BL6/J male mice were decalcified in 4\% EDTA and paraffin embedded following manufacturer's standard procedures (Histion, Everett, WA). Bones were sectioned in the sagittal plane to obtain cross sections of the distal femur and stained with hematoxylin and eosin (H\&E). Fields were taken from distal femur sections of 6-month-old and 14-month-old mice and adipose areas calculated using ImagePro software.

\section{Microarray analysis}

\section{RNA isolation, purification and array procedures}

Total RNA was extracted using Trizol (Life Technologies, Grand Island, NY, USA) and chloroform followed by purification on an RNeasy MinElute column (QIAGEN, Valencia, CA, USA). Three pooled RNA preparations were generated from 6-10 animals due to the low yield of bone marrow adipocytes during isolation. RNA quality was verified using an Agilent Bioanalyzer (Agilent technologies, Palo Alto, CA, USA). Total RNA was biotin-labeled and hybridized to the GeneChip Mouse Gene 1.0 ST Array platform (Affymetrix, Santa Clara, CA, USA) with three RNA preparations per age group. The Protein and Nucleic Acid Microarray Facility at Stanford University carried out processing of DNA arrays according to standard protocols from the Affymetrix GeneChip ${ }^{\mathbb{B}}$ Whole Transcript (WT) Sense Target Labeling Assay. This assay is designed to generate amplified and biotinylated sense-strand DNA targets from the entire expressed genome without bias. This assay and associated reagents have been optimized specifically for use with the GeneChip ${ }^{\circledR}$ ST Arrays where "ST" stands for "Sense Target" and the probes on the arrays have been selected to be distributed throughout the entire length of each transcript. The microarray data files have been submitted to the Gene Expression Omnibus (GEO) and the accession number is GSE25905.

\section{Statistical analysis}

The raw data from microarrays were analyzed using Partek $^{\mathbb{R}}$ Genome Suite software, version 6.3 Copyright $^{\mathcal{O}} 2008$ (Partek Inc., St. Louis, MO, USA). Briefly, Affymetrix .CEL files were processed to generate gcRMA (robust multiarray average) values. This step was followed by quantile normalization and $\log 2$ transformation to represent gene expression levels. Samples were grouped into cell type (bone marrow adipocytes vs. epididymal white adipocytes) and age (6-month (6M), 14-month (14M) and 18-month $(18 \mathrm{M}))$. ANOVA was performed including age and cell type interaction to generate the lists of differentially expressed genes comparing the bone marrow adipocytes with epididymal white adipocytes with age. There were three gene chips for each group. A total of 18 individual arrays contributed to the analyses. Probe sets with a foldchange 2.0 and adjusted $p$-value $<0.05$ were considered differentially expressed between two cell types at each age group. The Benjamini-Hochberg false discovery rate (FDR) method was used for false positives. A corrected p-value cutoff of 0.05 was used to select the regulated genes with the lowest FDR. Partek ${ }^{\circledR}$ Genome Suite was used as the first step for quality control (QC) of the data on all the samples with two methods, Pearson correlation and Principal Component Analysis (PCA). PCA was performed as a global view of sample clustering, which is related to the total variance in gene expression for all genes. Normalized expression values for all genes were analyzed. A selection of 3918 genes $(13 \%)$ of the 28853 well-characterized mouse genes in Mouse Gene 1.0 ST array was differentially 
expressed between the two adipocyte populations. This selection was based on adjusted $\mathrm{p}<0.05$ and fold change \pm 2.0. These 3918 genes were assigned to biologically meaningful gene ontology (GO) categories using GO enrichment analysis (Partek ${ }^{\circledR}$ Genome Suite software, version 6.3).

Statistical analysis of metabolic parameters was performed using Graphpad Prism 4.0. Age dependent changes were statistically analyzed by one-way ANOVA (repeated measures for within subject samples). Data are presented as mean $\pm \mathrm{SE}$.

\section{Pathway Analysis}

For each comparison a list of differentially expressed genes was generated. The gene lists, along with associated expression or fold-change values, were further analyzed using Ingenuity Pathway Analysis (Ingenuity system, Inc, Redwood City, CA, USA) to identify differentially expressed pathways between bone marrow adipocytes and epididymal white adipocytes with age. The list of significantly regulated genes selected by the microarray analysis described above was loaded in IPA with the following criteria: reference set: Mouse 1.0 ST Gene assay; direct and indirect relationships included filtered by species (mouse) and by tissue (adipose). Then IPA computed the data to generate significant networks of genes that are associated with particular biological functions, diseases and signaling pathways.

\section{Analysis of gene expression by real-time RT-PCR}

Total RNA was extracted from cells with TriZol reagent (Invitrogen, Carlsbad, CA, USA) according to the manufacturer's protocol. Total RNA was reverse transcribed with random hexamers by using reverse transcriptase (Invitrogen, Carlsbad, CA, USA). Expression of selected adipose genes in preparations of bone marrow cells, adipocytes isolated from bone marrow and adipocytes isolated from epididymal white adipose tissue. A set of original RNA from the same animal was re-amplified to aRNA, and then converted to cDNA. After cDNA synthesis, mRNA expression levels were determined by using SYBR green qPCR supermix (ABI, Foster City, CA, USA). Expression levels of mRNA were analyzed by quantitative real-time PCR (Prism 7900 Sequence Detection System, Applied Biosystems (ABI), Foster City, CA, USA). Relative gene expression was calculated using the comparative threshold method $(2-\Delta \Delta \mathrm{Ct})$ [53]. Relative fold change was normalized to endogenous $18 \mathrm{~S}$ and bone marrow stromal cells. Data are presented as $\log 2$ of fold change. Primers are listed in Additional File 2, Table S1.

\section{Determination of insulin and adipokine concentrations by Luminex ELISA}

Serum obtained from mice was analyzed for adipokines and bone panel measurements using a multiplex mouse adipokines assay (Mouse adipocyte panel, Millipore, Bedford, MA, USA), and detected by Luminex xMAP method (Luminex 200, Millipore, Bedford, MA, USA). Insulin and adipokines including adiponectin, leptin, resistin, and bone markers osteocalcin, RANKL and osteoprotegerin were measured in 6-month and 14month-old mice in the fed state.

\section{Immunostaining}

Percentage of monocytes was determined by counting the number of CD11b positive cells per 100 cells. Approximately 200 to 400 cells were counted in each experiment. Freshly isolated adipocytes from bone marrow or epididymal adipose tissue were fixed with $3.7 \%$ paraformaldehyde in PBS for $1 \mathrm{~h}$ at room temperature. Fixed cells were incubated with either BODIPY 493/503 (1:500, $1 \mathrm{mg} / \mathrm{mL}$, Molecular Probe, Carlsbad, CA, USA) or PE (phycoerythrin) conjugated anti-mouse CD11b (Intergrin a, Mac-1 $\alpha$, eBioscience Inc, San Diego, CA, USA) at $0.124 \mu$ g per million cells in $100 \mu \mathrm{L}$ total staining volume and polyclonal anti rabbit perilipin antibodies (1:200; a kind gift of Dr. Andrew Greenberg, Tufts University) in 1\% blocking solution for $1 \mathrm{~h}$. Following $1 \mathrm{~h}$ incubation of Alexa 555 (red) conjugated secondary antibodies at a dilution of 1:800 at room temperature, the stained cells were washed three to four times with PBS and observed using a Zeiss Axio Observer A1 microscope (Carl Zeiss, Thornwood, NY, USA).

\section{Additional material}

Additional file 1: Figure S1: Evaluation of gene expression microarray data sets. RNA from bone marrow and epididymal white adipocytes (three samples each age group) was converted to CDNA, labeled and hybridized to Affymetrix Mouse Gene 1.0 ST arrays. Scanned data were imported into Partek Genomics Suit Software and normalized using RMA algorithim. A plot of frequency versus signal value is shown for each dataset.

Additional file 2: Table S1: List of primers for qRT-PCR.

\section{Acknowledgements and Funding}

This research was supported in part by the Department of Veterans Affairs (Office of Research and Development, Medical Research Service) and by grant R01 AG028098 from the National Institutes of Health. We would like to thank the staff at the Protein and Nucleic Acid Microarray Facility at Stanford University who carried out processing of DNA arrays.

\section{Author details}

'Division of Endocrinology, Stanford University, Stanford, CA, 94305-5103, USA. ${ }^{2}$ VA Palo Alto Health Care System, Palo Alto, California, 94304, USA.

\section{Authors' contributions}

LFL designed and performed experiments and wrote the manuscript; WJS, MU and SP performed experiments; FBK designed the experiments and wrote the manuscript.

Received: 9 February 2011 Accepted: 5 May 2011 Published: 5 May 2011 


\section{References}

1. Cartwright MJ, Tchkonia T, Kirkland JL: Aging in adipocytes: potential impact of inherent, depot-specific mechanisms. Exp Gerontol 2007, 42:463-471.

2. Cartwright MJ, Schlauch $K$, Lenburg ME, Tchkonia T, Pirtskhalava T, Cartwright A, et al: Aging, depot origin, and preadipocyte gene expression. J Gerontol A Biol Sci Med Sci 2010, 65:242-251.

3. Kirkland JL, Tchkonia T, Pirtskhalava T, Han J, Karagiannides I: Adipogenesis and aging: does aging make fat go MAD? Exp Gerontol 2002, 37:757-767.

4. Tchkonia T, Morbeck DE, von Zglinicki T, van Deursen J, Lustgarten J, Scrable H, et al: Fat tissue, aging, and cellular senescence. Aging Cell 2010, 9:667-684.

5. Duque G: Bone and fat connection in aging bone. Curr Opin Rheumatol 2008, 20:429-434.

6. Rosen CJ, Bouxsein ML: Mechanisms of disease: is osteoporosis the obesity of bone? Nat Clin Pract Rheumatol 2006, 2:35-43.

7. Verma S, Rajaratnam JH, Denton J, Hoyland JA, Byers RJ: Adipocytic proportion of bone marrow is inversely related to bone formation in osteoporosis. J Clin Pathol 2002, 55:693-698.

8. Pond CM: Physiological specialisation of adipose tissue. Prog Lipid Res 1999, 38:225-248.

9. Unami A, Shinohara $Y$, Kajimoto K, Baba $Y$ : Comparison of gene expression profiles between white and brown adipose tissues of rat by microarray analysis. Biochem Pharmacol 2004, 67:555-564.

10. Abate N, Garg A, Peshock RM, Stray-Gundersen J, Grundy SM: Relationships of generalized and regional adiposity to insulin sensitivity in men. $J$ Clin Invest 1995, 96:88-98.

11. Caprio S, Hyman LD, McCarthy S, Lange R, Bronson M, Tamborlane WV: Fat distribution and cardiovascular risk factors in obese adolescent girls: importance of the intraabdominal fat depot. Am J Clin Nutr 1996, 64:12-17.

12. Gimble JM, Robinson CE, Wu X, Kelly KA: The function of adipocytes in the bone marrow stroma: an update. Bone 1996, 19:421-428.

13. Lecka-Czernik B, Moerman EJ, Grant DF, Lehmann JM, Manolagas SC, Jilka RL: Divergent effects of selective peroxisome proliferator-activated receptor-gamma 2 ligands on adipocyte versus osteoblast differentiation. Endocrinology 2002, 143:2376-2384.

14. Liu LF, Shen WJ, Zhang ZH, Wang LJ, Kraemer FB: Adipocytes decrease Runx2 expression in osteoblastic cells: Roles of PPARgamma and adiponectin. J Cell Physiol 2010, 225:837-845.

15. Linkhart TA, Linkhart SG, Kodama Y, Farley JR, Dimai HP, Wright KR et al: Osteoclast formation in bone marrow cultures from two inbred strains of mice with different bone densities. J Bone Miner Res 1999, 14:39-46.

16. Ferron M, Wei J, Yoshizawa $T$, Del Fattore $A$, DePinho RA, Teti $A$, et al: Insulin signaling in osteoblasts integrates bone remodeling and energy metabolism. Cell 2010, 142:296-308.

17. Fulzele K, Riddle RC, DiGirolamo DJ, Cao X, Wan C, Chen D, et al: Insulin receptor signaling in osteoblasts regulates postnatal bone acquisition and body composition. Cell 2010, 142:309-319.

18. Shinoda Y, Yamaguchi M, Ogata N, Akune T, Kubota N, Yamauchi T, et al: Regulation of bone formation by adiponectin through autocrine/ paracrine and endocrine pathways. J Cell Biochem 2006, 99:196-208.

19. Yokota T, Meka CS, Medina KL, Igarashi H, Comp PC, Takahashi M, et al: Paracrine regulation of fat cell formation in bone marrow cultures via adiponectin and prostaglandins. J Clin Invest 2002, 109:1303-1310.

20. Majka SM, Fox KE, Psilas JC, Helm KM, Childs CR, Acosta AS, et al: De novo generation of white adipocytes from the myeloid lineage via mesenchymal intermediates is age, adipose depot, and gender specific Proc Natl Acad Sci USA 2010, 107:14781-14786

21. Lara-Castro C, Garvey WT: Intracellular lipid accumulation in liver and muscle and the insulin resistance syndrome. Endocrinol Metab Clin North Am 2008, 37:841-856.

22. Lutz W, Sanderson W, Scherbov S: The coming acceleration of global population ageing. Nature 2008, 451:716-719.

23. Wang YC, Colditz GA, Kuntz KM: Forecasting the obesity epidemic in the aging U.S. population. Obesity (Silver Spring) 2007, 15:2855-2865.

24. Naveiras O, Nardi V, Wenzel PL, Hauschka PV, Fahey F, Daley GQ: Bonemarrow adipocytes as negative regulators of the haematopoietic microenvironment. Nature 2009, 460:259-263.
25. Persson J, Degerman E, Nilsson J, Lindholm MW: Perilipin and adipophilin expression in lipid loaded macrophages. Biochem Biophys Res Commun 2007, 363:1020-1026

26. Luo N, Liu J, Chung BH, Yang Q, Klein RL, Garvey WT, et al: Macrophage adiponectin expression improves insulin sensitivity and protects against inflammation and atherosclerosis. Diabetes 2010, 59:791-799.

27. Birsoy K, Chen Z, Friedman J: Transcriptional regulation of adipogenesis by KLF 4. Cell Metab 2008, 7:339-347.

28. Carnevalli LS, Masuda K, Frigerio F, Le Bacquer O, Um SH, Gandin V, et al: S6K1 plays a critical role in early adipocyte differentiation. Dev Cell 2010, 18:763-774.

29. Zaragosi LE, Wdziekonski B, Villageois P, Keophiphath M, Maumus M, Tchkonia T, et al: Activin A Plays a Critical Role in Proliferation and Differentiation of Human Adipose Progenitors. Diabetes 2010, 59:2513-2521.

30. Imamura M, Inoguchi T, Ikuyama S, Taniguchi S, Kobayashi K, Nakashima N, et al: ADRP stimulates lipid accumulation and lipid droplet formation in murine fibroblasts. Am J Physiol Endocrinol Metab 2002, 283:E775-E783.

31. Guo W, Pirtskhalava T, Tchkonia T, Xie W, Thomou T, Han J, et al: Aging results in paradoxical susceptibility of fat cell progenitors to lipotoxicity. Am J Physiol Endocrinol Metab 2007, 292:E1041-E1051.

32. Wu D, Ren Z, Pae M, Guo W, Cui X, Merrill AH, et al: Aging up-regulates expression of inflammatory mediators in mouse adipose tissue. $J$ Immunol 2007, 179:4829-4839.

33. Linford NJ, Beyer RP, Gollahon K, Krajcik RA, Malloy VL, Demas V, et al: Transcriptional response to aging and caloric restriction in heart and adipose tissue. Aging Cell 2007, 6:673-688.

34. Higami Y, Pugh TD, Page GP, Allison DB, Prolla TA, Weindruch R: Adipose tissue energy metabolism: altered gene expression profile of mice subjected to long-term caloric restriction. FASEB J 2004, 18:415-417.

35. Karagiannides I, Tchkonia T, Dobson DE, Steppan CM, Cummins P, Chan G, et al: Altered expression of C/EBP family members results in decreased adipogenesis with aging. Am J Physiol Regul Integr Comp Physiol 2001, 280: R1772-R1780.

36. Phielix E, Szendroedi J, Roden M: Mitochondrial Function and Insulin Resistance during Aging - A Mini-Review. Gerontology

37. Roden M: Muscle triglycerides and mitochondrial function: possible mechanisms for the development of type 2 diabetes. Int J Obes (Lond) 2005, 29(Suppl 2):S111-S115.

38. Szendroedi J, Schmid Al, Chmelik M, Toth C, Brehm A, Krssak M, et al: Muscle mitochondrial ATP synthesis and glucose transport/ phosphorylation in type 2 diabetes. PLoS Med 2007, 4:e154.

39. Szendroedi J, Roden M: Mitochondrial fitness and insulin sensitivity in humans. Diabetologia 2008, 51:2155-2167.

40. Ungvari Z, Labinskyy N, Gupte S, Chander PN, Edwards JG, Csiszar A Dysregulation of mitochondrial biogenesis in vascular endothelial and smooth muscle cells of aged rats. Am J Physiol Heart Circ Physiol 2008, 294: $\mathrm{H} 2121-\mathrm{H} 2128$

41. Ungvari Z, Sonntag WE, Csiszar A: Mitochondria and aging in the vascular system. J Mol Med 2010, 88:1021-1027.

42. Landis GN, Tower J: Superoxide dismutase evolution and life span regulation. Mech Ageing Dev 2005, 126:365-379.

43. Wu Y, Smas CM: Wdnm1-like, a new adipokine with a role in MMP-2 activation. Am J Physiol Endocrinol Metab 2008, 295:E205-E215.

44. Allori AC, Sailon AM, Warren SM: Biological basis of bone formation, remodeling, and repair-part I: biochemical signaling molecules. Tissue Eng Part B Rev 2008, 14:259-273.

45. Boyce BF, Xing L: Functions of RANKL/RANK/OPG in bone modeling and remodeling. Arch Biochem Biophys 2008, 473:139-146.

46. Nakanishi R, Shimizu M, Mori M, Akiyama H, Okudaira S, Otsuki B, et al: Secreted frizzled-related protein 4 is a negative regulator of peak BMD in SAMP6 mice. J Bone Miner Res 2006, 21:1713-1721.

47. Park JR, Jung JW, Lee YS, Kang KS: The roles of Wnt antagonists Dkk1 and sFRP4 during adipogenesis of human adipose tissue-derived mesenchymal stem cells. Cell Prolif 2008, 41:859-874.

48. White KE, Larsson TE, Econs MJ: The roles of specific genes implicated as circulating factors involved in normal and disordered phosphate homeostasis: frizzled related protein-4, matrix extracellular phosphoglycoprotein, and fibroblast growth factor 23. Endocr Rev 2006, 27:221-241. 
49. Nakanishi R, Akiyama H, Kimura H, Otsuki B, Shimizu M, Tsuboyama T, et al: Osteoblast-targeted expression of Sfrp4 in mice results in low bone mass. J Bone Miner Res 2008, 23:271-277.

50. Oude Elferink RP, Paulusma CC: Function and pathophysiological importance of ABCB4 (MDR3 P-glycoprotein). Pflugers Arch 2007, 453:601-610.

51. Gille A, Bodor ET, Ahmed K, Offermanns S: Nicotinic acid: pharmacological effects and mechanisms of action. Annu Rev Pharmacol Toxicol 2008, 48:79-106.

52. Shen WJ, Patel $S, Y u Z$, Jue D, Kraemer FB: Effects of rosiglitazone and high fat diet on lipase/esterase expression in adipose tissue. Biochim Biophys Acta 2007, 1771:177-184.

53. Livak KJ, Schmittgen TD: Analysis of relative gene expression data using real-time quantitative PCR and the 2(-Delta Delta $C(T))$ Method. Methods 2001, 25:402-408.

doi:10.1186/1471-2164-12-212

Cite this article as: Liu et al: Characterization of age-related gene expression profiling in bone marrow and epididymal adipocytes. BMC Genomics 2011 12:212.

\section{Submit your next manuscript to BioMed Central} and take full advantage of:

- Convenient online submission

- Thorough peer review

- No space constraints or color figure charges

- Immediate publication on acceptance

- Inclusion in PubMed, CAS, Scopus and Google Scholar

- Research which is freely available for redistribution

Submit your manuscript at www.biomedcentral.com/submit
C Biomed Central 